OPEN ACCESS

Edited by:

Hongkui Wei,

Huazhong Agricultural University,

China

Reviewed by:

Yanjiao Zhang,

Ocean University of China, China

Shiwei Xie,

Guangdong Ocean University, China

${ }^{*}$ Correspondence: Naisong Chen

nschen@shou.edu.cn

Songlin $\mathrm{Li}$

sli@shou.edu.cn

${ }^{t}$ These authors have contributed equally to this work

Specialty section: This article was submitted to Nutritional Immunology, a section of the journal

Frontiers in Immunology

Received: 02 December 2021 Accepted: 20 December 2021

Published: 11 January 2022

Citation:

Wang S, Han Z, Turchini GM, Wang X, Fang Z, Chen N, Xie R,

Zhang $H$ and Li S (2022) Effects of Dietary Phospholipids on Growth Performance, Digestive Enzymes Activity and Intestinal Health of Largemouth Bass (Micropterus salmoides) Larvae.

Front. Immunol. 12:827946 doi: 10.3389/fimmu.2021.827946

\section{Effects of Dietary Phospholipids on Growth Performance, Digestive Enzymes Activity and Intestinal Health of Largemouth Bass (Micropterus salmoides) Larvae}

\author{
Shilin Wang ${ }^{1 \dagger}$, Zhihao Han ${ }^{1 \dagger}$, Giovanni M. Turchini ${ }^{2}$, Xiaoyuan Wang ${ }^{1}$, Zishuo Fang ${ }^{1}$, \\ Naisong Chen ${ }^{1 *}$, Ruitao Xie ${ }^{3}$, Haitao Zhang ${ }^{3}$ and Songlin $\mathrm{Li}^{{ }^{*}}$ \\ ${ }^{1}$ Research Centre of the Ministry of Agriculture and Rural Affairs on Environmental Ecology and Fish Nutrition, Shanghai \\ Ocean University, Shanghai, China, 2 School of Life and Environmental Sciences, Deakin University, Geelong, VIC, Australia, \\ ${ }^{3}$ Key Laboratory of Aquatic, Livestock and Poultry Feed Science and Technology in South China, Ministry of Agriculture and \\ Rural Affairs, Zhaniiang, China
}

While the beneficial roles of dietary phospholipids on health status and overall performances of fish larvae have been well demonstrated, the underlying mechanisms remain unclear. To address this gap, the present study was conducted to investigate the effects of dietary phospholipids on growth performance, intestinal development, immune response and microbiota of larval largemouth bass (Micropterus salmoides). Five isonitrogenous and isolipidic micro-diets were formulated to contain graded inclusion levels of phospholipids (1.69, 3.11, 5.23, 7.43 and 9.29\%). Results showed that the supplementation of dietary phospholipids linearly improved the growth performance of largemouth bass larvae. The inclusion of dietary phospholipids increased the activity of digestive enzymes, such as lipase, trypsin and alkaline phosphatase, and promoted the expression of tight junction proteins including ZO-1, claudin-4 and claudin-5. Additionally, dietary phospholipids inclusion alleviated the accumulation of intestinal triacylglycerols, and further elevated the activity of lysozyme. Dietary phospholipids inhibited the transcription of some pro-inflammatory cytokines, including il-1 $\beta$, and tnf- $\alpha$, but promoted the expression of anti-inflammatory cytokines $\operatorname{tgf}$ - $\beta$, with these modifications being suggested to be mediated by the p38MAPK/Nf- $\kappa \mathrm{B}$ pathway. The analysis of bacterial 16S rRNA V3-4 region indicated that the intestinal microbiota profile was significantly altered at the genus level with dietary phospholipids inclusion, including a decreased richness of pathogenic bacteria genera Klebsiella in larval intestine. 
In summary, it was showed that largemouth bass larvae have a specific requirement for dietary phospholipids, and this study provided novel insights on how dietary phospholipids supplementation contributes to improving the growth performance, digestive tract development and intestinal health.

Keywords: phospholipids, larval fish, intestinal development, immune response, gut microbiota

\section{INTRODUCTION}

Phospholipids are phosphorus containing lipids with several important structural and functional roles $(1,2)$. It is well demonstrated that the limited biosynthetic capacity in larval stages of most fish species makes phospholipids essential nutrients, and accordingly they have to be supplemented in larval diets (3). The provision of appropriate dietary phospholipids is beneficial in improving growth performance, digestive tract development, antioxidant capacity and stress resistance (4-7). However, there are still a series of unclarified physiological considerations and mechanisms that might contribute to the explanation of how dietary phospholipids affect digestive and intestinal development and health in larval fish.

In addition to limited phospholipid biosynthetic capacity, larval fish also possess an immature digestive tract, whereas welldeveloped and functioning digestive organs are essential to digest the feed and absorb its nutrients (Zambonino 8). Extensive literatures revealed that dietary nutrient composition directly influences the development of digestive tract in fish larvae $(3,9$, 10). Notably, the maturation of digestive functions has been associated with dietary phospholipids content in several larval fish, such as European seabass (Dicentrarchus labrax) (4), pikeperch (Sander lucioperca) (5) and large yellow croaker (Larmichthys crocea) (6). Importantly, in all these studies the maturation of the digestive tract was assessed by measuring the activity of intestinal enzymes such as lipase, amylase, trypsin and alkaline phosphatase. However, within this context, little research attention has thus far been given to tight junctions. These are intercellular junctions, which are essential for epithelial adhesion and barrier function in various kind of tissues and organs, including the digestive system (11). The tight junctions have been suggested to regulate the intercellular structural integrity of intestine in some juvenile fish including gilthead seabream (Sparus aurata) (12), grass carp (Ctenopharyngodon idella) (13), and largemouth bass (Micropterus salmoides) (14). Nevertheless, little information is currently available on the influence of dietary phospholipids on tight junctions in fish larvae.

Phospholipids are important components of chylomicrons, which are central for lipid transport (15), but the enterocytes of larval fish possess limited phospholipid biosynthetic capability (16). Thus, a dietary phospholipid deficiency in fish larvae commonly results in excessive lipid deposition in intestinal enterocytes (17-19), which, in turn, is commonly associated with chronic inflammation $(20,21)$. The p38 mitogen-activated protein kinases (MAPK), a member of MAPK family, is involved in the regulation of several cellular processes, including

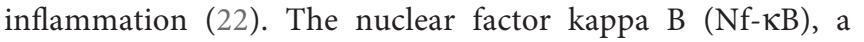
downstream target of the p38 MAPK signaling pathway, is a major signaling molecule in the regulation of cytokines production (23). Therefore, it has been suggested that, in teleosts, the p38 MAPK/Nf- $\kappa \mathrm{B}$ pathway participates in the regulation of inflammation response $(20,24)$. However, it is yet unclear whether dietary phospholipids can alleviate the intestinal inflammation response in fish larvae through the p38 MAPK/Nf- $\kappa \mathrm{B}$ pathway.

Another important consideration when it comes to digestive and intestinal health in larval fish is the intestinal microbiota (25). The diversity and abundance of intestinal microbiota influence a wide range of host biological processes such as digestion, mucosal system development, and disease resistance $(26,27)$. Growing evidence revealed that the dietary composition is affecting the intestinal microbiome in most fish species (28-30). Therefore, the possible beneficial roles of dietary phospholipids on the development of intestine in fish larvae may also be partly related to the variation in intestinal microbiota. However, little information is currently available on the influence of dietary phospholipids on intestinal microbiota.

Considering the points introduced above, and aiming at contributing to current knowledge of the roles of dietary phospholipids on the overall performance of fish larvae, the present study focused on assessing the effects of dietary phospholipids on growth performance, digestive enzymes activity, antioxidant capacity, immune response and intestinal microbiome of larval largemouth bass. Largemouth bass was chosen as target species as it has important socioeconomic considerations, as its production in China has reached 600,000 tons in 2020 (31). Previous studies mainly focused on the nutritional physiology research of juvenile largemouth bass (32-36). However, on farm, the survival rate of this fish larvae is reported to be as little as $3 \%$, which represents an important bottleneck for the further development of this aquaculture sector. As such, any knowledge gain in larval nutrition of this species would have dramatic positive effects on this industrial sector, as well as it would contribute to current fundamental knowledge of fish nutrition.

\section{MATERIALS AND METHODS}

\section{Experimental Diets}

Five isonitrogenous, isoenergetic and isolipidic diets were formulated with graded supplementation of soybean 
phospholipids, 0\% (control, PL0), 2\% (PL2), 4\% (PL4), 6\% (PL6) and 8\% (PL8), and the resulting measured value of dietary phospholipids content was $1.69,3.11,5.23,7.43$, and 9.29\%, respectively (Table 1). Diets were manufactured following previously described procedures (36). Briefly, after thorough mixing of the dry ingredients, water was added to the mixture to make a stiff dough, which was then extruded through a $1.0 \mathrm{~mm}$ die by a pelleting machine, and dried in a ventilated oven at $55^{\circ} \mathrm{C}$. Then, the experimental diets were ground to crumbles of four different particle sizes, 180-250 $\mu \mathrm{m}$, 250-380 $\mu \mathrm{m}, 380-830 \mu \mathrm{m}$ and above $830 \mu \mathrm{m}$, which were stored at $-20^{\circ} \mathrm{C}$ until being used.

\section{Experimental Procedure}

The in vivo feeding trail was conducted at the joint laboratory of Shanghai Ocean University and Guangdong Evergreen Feed Industry Co., Ltd (Zhanjiang, China), and all procedures of this study were performed following the guide for the use of experimental animals of Shanghai Ocean University. Largemouth bass larvae (7 DPH, days post hatching) were provided by a local commercial hatchery in Foshan city (Guangdong, China). Larvae were fed with newly hatched artemia for three days, and then weaned to adapt a dried commercial micro-diet by alternate feeding artemia and micro-diet over a six days' period. Then, larvae (17 DPH) with initial body weight of $9.61 \pm 0.02 \mathrm{mg}$ were divided into 15 tanks (water volume $1000 \mathrm{~L}$ ) with the destiny of 2500 individuals per tank. Following a random allocation, triplicates groups of larvae were fed the experimental diets to apparent satiation five times daily $(6: 00,9: 00,12: 00,15: 00$, and
18:00) for 28 days. The larvae were gradually fed the diet with particle size of $180-250 \mu \mathrm{m}$ (body weight $\leq 0.10 \mathrm{~g}$ ), $250-380 \mu \mathrm{m}$ $(0.10 \mathrm{~g}<$ body weight $\leq 0.50 \mathrm{~g}), 380-830 \mu \mathrm{m}(0.50 \mathrm{~g}<$ body weight $\leq 0.80 \mathrm{~g}$ ) and above $830 \mu \mathrm{m}$ (body weight $>0.80 \mathrm{~g}$ ). The water quality was monitored during the feeding trail to maintain within optimal conditions: temperature, $27 \pm 1^{\circ} \mathrm{C}$; $\mathrm{pH}, 7.2 \pm 0.2$; dissolved oxygen $\geq 6 \mathrm{mg} / \mathrm{L}$.

\section{Sampling}

The initial body weight and body length of 100 randomly collected largemouth bass larvae were measured at the beginning of the feeding trail. At the termination of the in vivo study, the weight and number of fish larvae were recorded to calculate the survival rate and growth performance. Before final weighing, fish were fasted for $24 \mathrm{~h}$ and then anaesthetized with eugenol (1:10000; Shanghai Reagent Corp., Shanghai, China). Thirty larvae were randomly collected and sacrificed to measure the individual body weight and body length, and were then used for the body composition analysis. Another sixty fish were sacrificed and dissected to collect liver and intestinal samples for the analysis of enzyme activity, gene expression and microbiome.

\section{Chemical Composition Analysis}

The moisture content was determined through drying samples at $105^{\circ} \mathrm{C}$ to a constant weight (37). Crude protein content was measured with the Kjeldahl method through the measurement of nitrogen content $(\mathrm{N} \times 6.25)$ (37). Crude lipid content was assayed by the chloroform-methanol extraction method (38) with some modification described in Peng etal. (39). Dietary

TABLE 1 | Formulation and proximate composition of experimental diets ( $\mathrm{mg} / \mathrm{g}$ dry matter).

\begin{tabular}{|c|c|c|c|c|c|}
\hline \multirow[t]{2}{*}{ Ingredients } & \multicolumn{5}{|c|}{ Diets } \\
\hline & PLO & PL2 & PL4 & PL6 & PL8 \\
\hline White fish meal ${ }^{\mathrm{a}}$ & 580.0 & 580.0 & 580.0 & 580.0 & 580.0 \\
\hline Hydrolyzed fish paste $^{a}$ & 80.0 & 80.0 & 80.0 & 80.0 & 80.0 \\
\hline Sodium caseinate ${ }^{a}$ & 40.0 & 40.0 & 40.0 & 40.0 & 40.0 \\
\hline Fermented soybean meal $^{\mathrm{a}}$ & 42.0 & 42.0 & 42.0 & 42.0 & 42.0 \\
\hline Blood meal $^{a}$ & 20.0 & 20.0 & 20.0 & 20.0 & 20.0 \\
\hline Wheat gluten meal ${ }^{a}$ & 25.0 & 25.0 & 25.0 & 25.0 & 25.0 \\
\hline Shrimp meal ${ }^{\mathrm{a}}$ & 40.0 & 40.0 & 40.0 & 40.0 & 40.0 \\
\hline Bread yeast hydrolysate ${ }^{a}$ & 5.00 & 5.00 & 5.00 & 5.00 & 5.00 \\
\hline Fish oil & 15.0 & 15.0 & 15.0 & 15.0 & 15.0 \\
\hline $\mathrm{Ca}\left(\mathrm{H}_{2} \mathrm{PO}_{3}\right)_{2}$ & 10.0 & 10.0 & 10.0 & 10.0 & 10.0 \\
\hline Vitamin mixture $^{b}$ & 13.0 & 13.0 & 13.0 & 13.0 & 13.0 \\
\hline Mineral mixture ${ }^{c}$ & 10.0 & 10.0 & 10.0 & 10.0 & 10.0 \\
\hline$\alpha-$ Starch $^{a}$ & 40.0 & 40.0 & 40.0 & 40.0 & 40.0 \\
\hline Soybean phospholipids ${ }^{a}$ & 0.0 & 20.0 & 40.0 & 60.0 & 80.0 \\
\hline Soybean oil ${ }^{\mathrm{a}}$ & 80.0 & 60.0 & 40.0 & 20.0 & 0.00 \\
\hline \multicolumn{6}{|c|}{ Proximate analysis (Mean values, mg/g dry weight) } \\
\hline Crude protein & 607.5 & 603.0 & 606.8 & 605.6 & 605.3 \\
\hline Crude lipid & 139.5 & 137.4 & 133.3 & 133.0 & 136.9 \\
\hline Phospholipids & 16.9 & 31.1 & 52.3 & 74.3 & 92.9 \\
\hline
\end{tabular}

aSupplied by Xinxin Tian'en Aquatic Feed Co., Ltd (Zhejiang, China).

${ }^{b}$ Vitamin Premix (mg/kg diet): vitamin A, $16000 \mathrm{IU}$; vitamin $D_{3}, 8000 \mathrm{IU}$; vitamin $K_{3}, 14.72$; vitamin $B_{1}, 17.80 ;$ vitamin $B_{2}, 48 ;$ vitamin $B_{6}, 29.52 ;$ vitamin $B_{12}, 0.24 ;$ vitamin E, 160; vitamin C, 800; niacinamide, 79.20; calcium-pantothenate, 73.60; folic acid, 6.40; biotin, 0.64; inositol, 320; choline chloride, $1500 ;$ L-carnitine, 100.

${ }^{c}$ Mineral Premix (mg/kg diet): $\mathrm{Cu}\left(\mathrm{CuSO}_{4}\right), 2.00 ; \mathrm{Zn}\left(\mathrm{ZnSO}_{4}\right), 34.4 ; \mathrm{Mn}\left(\mathrm{MnSO}_{4}\right), 6.20 ; \mathrm{Fe}\left(\mathrm{FeSO}_{4}\right), 21.10 ; \mathrm{I}\left(\mathrm{Ca}\left(\mathrm{IO}_{3}\right)\right.$ 2), 1.63; Se $\left(\mathrm{Na}_{2} \mathrm{SeO} \mathrm{S}_{3}\right), 0.18 ; \mathrm{Co}(\mathrm{COCl}), 0.24 ; \mathrm{Mg}\left(\mathrm{MgSO}_{4} \cdot \mathrm{H}_{2} \mathrm{O}\right)$, 52.70. 
phospholipids content was assayed with the molybdenum blue method following the procedure described in Li etal. (40).

\section{Digestive Enzymes Activity Analysis}

The intestinal samples were homogenized in ice-cold phosphate buffer saline $(1: 9 ; \mathrm{w} / \mathrm{v})$, and then centrifuged at $5000 \mathrm{rpm}$ for $10 \mathrm{~min}$ at $4^{\circ} \mathrm{C}$ to separate the supernatant which was used for the analysis of digestive enzymes activity. The trypsin activity was measured by the trypsin assay kit (Nanjing Jiancheng BioEngineering Institute, China), and L-arginine ethyl ester was used as the reaction substrate. The activity of lipase was determined, with triglyceride as the substrate, by the lipase assay kit (Nanjing Jiancheng Bio-Engineering Institute). The amylase activity was assayed by evaluating the reduced amylase content with a commercial kit (Nanjing Jiancheng BioEngineering Institute). The activity of alkaline phosphatase was determined using disodium phenyl phosphate as reaction substrate with a commercial kit (Nanjing Jiancheng BioEngineering Institute). The soluble protein content was determined with the coomassie brilliant blue method (41), which content was measured to calculate the specific activity of digestive enzymes.

\section{Lysozyme Activity Analysis}

The lysozyme activity of intestine was determined using the turbidimetric method with a commercial lysozyme assay kit (Nanjing Jiancheng Bio-engineering Institute). Briefly, the transmittance was recorded at $20 \mathrm{~s}$ after samples being blended with the suspension of Micrococcus lysodeikticus. Then, the mixture was reacted at $37^{\circ} \mathrm{C}$ for $5 \mathrm{~min}$, and thereafter, the transmittance was recorded to calculate the lysozyme activity.

\section{Triglyceride Content Analysis}

The triacylglycerols (TAG) content in intestine was analyzed spectrophotochemically at $546 \mathrm{~nm}$ according to the colorimetric enzyme-linked TAG detection method described by Schwartz and Wolins (42) with a commercial TAG regent kit (Nanjing Jiancheng Bio-engineering Institute).

\section{RNA Extraction and Relative Gene Expression Analysis}

The relative expression of genes involved in immune response and intestinal barrier function was determined following previously described procedures (36). The primer sequences for the selected target genes, $p 38 \alpha$ mitogen-activated protein kinase ( $38 \alpha$ mapk/mapk14), p38 $\delta$ mapk (mapk 13), nuclear factorkappa B p65 (nf-kb p65/rela), interleukin-1 $\beta$ (il-1 $\beta)$, tumor necrosis factor- $\alpha$ (tnf- $\alpha)$, 5-lipoxygenase (5-lox), transforming growth factor- $\beta$ (tgf- $\beta)$, zona occludens-1 (zo-1), claudin-1, claudin-4, claudin-5 and $\beta$-actin were designed based on the corresponding sequences or referred to previously published studies $(14,43)$ (Table 2). The total RNA of whole intestine was extracted using RNAiso Plus (Takara, Japan), and then was reverse transcribed into single strand cDNA based on the description of $\mathrm{Li}$ et al. (21). The real-time quantitative PCR (RT-qPCR) was performed in a quantitative thermal cycler (CFX96, Bio-Rad, CA, USA) with the following procedure: $95^{\circ} \mathrm{C}, 2 \mathrm{~min}$; 40 cycles of $95^{\circ} \mathrm{C}$ for $10 \mathrm{~s}, 57^{\circ} \mathrm{C}$ for $10 \mathrm{~s}$, and $72^{\circ} \mathrm{C}$ for $20 \mathrm{~s}$. After the reaction, a melting curve analysis was performed to confirm the single PCR product in those reactions. The relative expression of target genes was calculated using the $2^{-\Delta \Delta \mathrm{Ct}}$ method (44), and $\beta$-actin was used as the housekeeping gene.

\section{DNA Extraction, Amplification, and Sequencing of Gut 16S rRNA Genes}

The bacterial DNA of the larvae in both the control group and PL8 group were extracted using the E.Z.N.A. ${ }^{\circledR}$ soil DNA Kit (Omega, USA) following the instructions of manufacturer. The integrity of DNA extract was determined on $1 \%$ agarose gel, and concentration and purity of the obtained DNA were measured with NanoDrop 2000 UV-vis spectrophotometer (Thermo Scientific, Wilmington, USA). Then, the V3-V4 region of the bacterial 16S rRNA gene was amplified with the 338F/806R primer set in a PCR thermocycler (ABI, USA). The PCR program was set as follows: $95^{\circ} \mathrm{C}$ for $3 \mathrm{~min}$, followed by 27 cycles of $95^{\circ} \mathrm{C}$ for $30 \mathrm{~s}, 55^{\circ} \mathrm{C}$ for $30 \mathrm{~s}$ and $72^{\circ} \mathrm{C}$ for $45 \mathrm{~s}$, and $72^{\circ} \mathrm{C}$ for $10 \mathrm{~min}$. Subsequently, the PCR product was extracted from $2 \%$ agarose gel, and purified with the AxyPrep DNA Gel

TABLE 2 | Sequences of the specific primers used in real-time quantitative PCR.

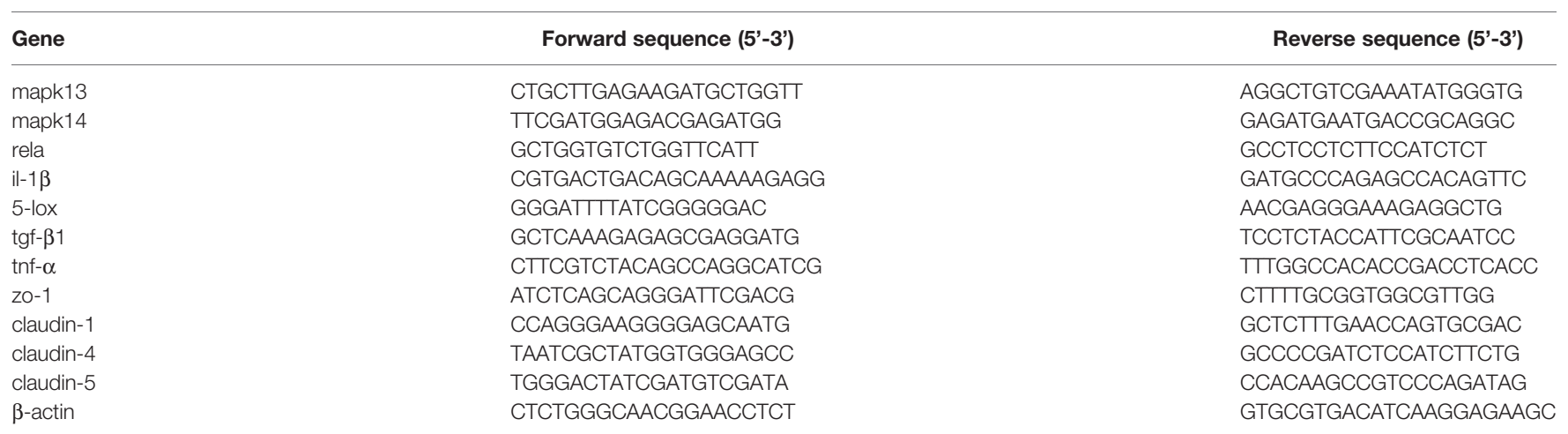

mapk13, mitogen-activated protein kinase 13; mapk14, mitogen-activated protein kinase 14; rela, nuclear factor-kappa B p65; il-1 $\beta$, interleukin-1 $\beta$; 5-lox, 5-lipoxygenase; tgf- $\beta 1$, transforming growth factor- $\beta 1$; thf- $\alpha$, tumor necrosis factor- $\alpha$; zo-1, zona occludens- 1 
Extraction Kit (Axygen, USA), and quantified using Quantus ${ }^{\mathrm{TM}}$ Fluorometer (Promega, USA). After that, the purified amplicons were sequenced on an Illumina MiSeq PE300 platform (Illumina, USA) by Majorbio Bio-Pharm Technology Co. Ltd. (Shanghai, China).

\section{Bioinformatic Analysis}

The raw DNA sequences were demultiplexed and quality-filtered to obtain the high-quality clean reads with the Quantitative Insights into Microbial Ecology (QIIME) quality filters (45), and thereafter, merged with the FLASH software (46). Then, operational taxonomic units (OTUs) with a $97 \%$ similarity cutoff were clustered using UPARSE, and then chimeric sequences were removed UCHIME Algorithm (47). The phylogenetic affiliation of each OTU representative sequence was analyzed by RDP Classifier against the $16 \mathrm{~S}$ rRNA database (eg. Silva v138), and a confidence threshold was set as $70 \%$ (48). The alpha diversity analysis, Shannon index, Simpson index, Ace index and Chao index, and beta diversity analysis, non-metric multidimensional scaling (NMDS) ordination, principal coordinates analysis (PCoA) and hierarchical clustering tree analysis, were calculated with QIIME and displayed with $\mathrm{R}$ software. Linear discriminant analysis (LDA) effect size (LefSe) analysis was used to identify the different abundant taxa between the two detected groups (49)

\section{Calculations and Statistical Analysis}

The growth performance of largemouth bass in response to dietary phospholipids inclusion were calculated as follows:

$$
\begin{aligned}
& \text { Survival rate }(\mathrm{SR}, \%) \\
& =\text { final fish number/initial fish number } \times 100 ;
\end{aligned}
$$

$$
\begin{aligned}
& \text { Specific growth rate }(\mathrm{SGR}, \% / \mathrm{d}) \\
& =(\operatorname{Ln}(\text { final body weight })-\operatorname{Ln}(\text { initial body weight })) \\
& \quad \times 100 / \text { days } .
\end{aligned}
$$

All of the statistical analysis were performed with SPSS version 19.0 (SPSS, Inc.). Polynomial contrasts (linear and quadratic) were used to test the effects of dietary phospholipids inclusion levels on the various variables measured in the present study after the data being tested for normality and homoscedasticity. When both linear and quadratic significant regressions were observed, linearity was selected as the simplest model for describing the observed trend. The level of significance was set at $P<0.05$, and the results are presented as mean values, plus or minus standard errors of means. The intestinal bacterial diversity and OTU richness were analyzed by the Welch's t-test with statistically significance being considered as $P<0.05$.

\section{RESULTS}

\section{Growth Performance}

The supplementation of dietary phospholipids significantly increased the final body weight and final body length in a positive linear manner $(P<0.05)$ (Table 3). The increasing levels of dietary phospholipids led to a direct linear increase of the specific growth rate, with the larvae of PL8 group obtained the maximum value $(P<0.05)$ (Table 3$)$. The survival rate also increased linearly with the increase of dietary phospholipids $(P<0.05)$, and the maximum content was observed in the PL8 group (Table 3).

\section{Body Approximate Composition}

The inclusion of phospholipids produced no significant influence on the moisture content of largemouth bass larvae $(P>0.05)$ (Table 4). However, the crude protein content was linearly related to the increase of dietary phospholipids $(P<0.05)$, and the maximum value was observed in the PL4 group (Table 4). The increase of dietary phospholipids led to a linear decrease of crude lipid content of whole fish body $(P<0.05)$ (Table 4$)$.

\section{Digestive Enzyme Activities}

The activity of amylase decreased as dietary phospholipids increased, although no linear, nor quadratic, response was observed $(P>0.05)$ (Table 5). However, the inclusion of dietary phospholipids led to a linear increase of lipase activity, and the maximum value was observed in PL8 group $(P<0.05)$ (Table 5). Meanwhile, the increase of dietary phospholipids linearly elevated the activity of trypsin increased with the maximum value being observed in the PL6

\begin{tabular}{|c|c|c|c|c|c|c|c|c|}
\hline & \multicolumn{5}{|c|}{ Diets } & \multirow[t]{2}{*}{ Pooled SEM } & \multicolumn{2}{|c|}{ Regression (P/R $\left.{ }^{2}\right)$} \\
\hline & PLO & PL2 & PL4 & PL6 & PL8 & & Linear & Quadratic \\
\hline IBW (mg) & 9.61 & 9.61 & 9.61 & 9.61 & 9.61 & n.a. & n.a. & n.a. \\
\hline FBW (g) & 0.28 & 0.66 & 0.71 & 0.79 & 1.23 & 0.08 & $<0.001 / 0.832$ & $<0.001 / 0.835$ \\
\hline IBL (cm) & 0.90 & 0.90 & 0.90 & 0.90 & 0.90 & n.a. & n.a. & n.a. \\
\hline $\mathrm{FBL}(\mathrm{cm})$ & 2.32 & 2.93 & 3.02 & 3.42 & 3.82 & 0.14 & $<0.001 / 0.886$ & $<0.001 / 0.887$ \\
\hline SR (\%) & 9.95 & 14.63 & 14.14 & 19.74 & 21.04 & 1.11 & $<0.001 / 0.849$ & $<0.001 / 0.850$ \\
\hline SGR (\%/day) & 12.91 & 15.62 & 16.10 & 16.17 & 17.81 & 0.43 & $<0.001 / 0.768$ & $<0.001 / 0.803$ \\
\hline
\end{tabular}
group $(P<0.05)$ (Table 5). The variation of alkaline phosphatase (AKP) followed a similar pattern with trypsin, and the maximum activity of AKP was achieved in the PL4 group $(P<0.05)$ (Table 5).

TABLE 3 | Growth performance of largemouth bass larvae fed the experimental diets for 28 days ${ }^{\star}$.

*Values are means of triplicate. SEM, standard error of means; n.a., not applicable; IBW, initial body weight; FBW, final body weight; IBL, initial body length; FBL, final body length; SR, survival rate; SGR, specific growth rate. 
TABLE 4 | Effects of dietary phospholipids on whole body composition of largemouth bass larvae fed the experimental diets for 28 days .

\begin{tabular}{|c|c|c|c|c|c|c|c|c|}
\hline & \multicolumn{5}{|c|}{ Diets } & \multirow[t]{2}{*}{ Pooled SEM } & \multicolumn{2}{|c|}{ Regression $\left(\mathbf{P} / \mathbf{R}^{2}\right)$} \\
\hline & PLO & PL2 & PL4 & PL6 & PL8 & & Linear & Quadratic \\
\hline Moisture (\%) & 79.11 & 77.01 & 77.70 & 77.51 & 77.32 & 0.25 & n.s. & n.s. \\
\hline Crude protein (\%) & 14.22 & 15.27 & 15.73 & 15.60 & 15.70 & 0.16 & $0.002 / 0.539$ & $<0.001 / 0.796$ \\
\hline Crude lipid (\%) & 4.32 & 5.00 & 4.05 & 3.78 & 4.00 & 0.12 & $0.017 / 0.366$ & n.s. \\
\hline
\end{tabular}

*Values are means of triplicate. SEM, standard error of means; n.s., no significant difference was observed.

\section{Relative mRNA Levels of Tight Junction Proteins}

The expression of $z o-1$ was increased in linear manner as dietary phospholipids increased $(P<0.05)$ (Figure 1). The supplementation of phospholipids significantly decreased the expression of claudin-1 in a negative linear manner $(P<0.05)$ (Figure 1). The expression of claudin-4 and claudin-5 was significantly followed an opposite pattern with that of claudin1 , and the lowest expression value was observed in larvae of the control group $(P<0.05)$ (Figure 1).

TABLE 5 | The activities of digestive enzymes in the intestine of largemouth bass larvae fed with experimental diets for 28 days ${ }^{\star}$.

\begin{tabular}{|c|c|c|c|c|c|c|c|c|}
\hline & \multicolumn{5}{|c|}{ Diets } & \multirow[t]{2}{*}{ Pooled SEM } & \multicolumn{2}{|c|}{ Regression (P/R $\left.{ }^{2}\right)$} \\
\hline & PLO & PL2 & PL4 & PL6 & PL8 & & Linear & Quadratic \\
\hline AMS (U/mgprot) & 0.56 & 0.40 & 0.50 & 0.48 & 0.41 & 0.02 & n.s. & n.s. \\
\hline LPS (U/gprot) & 24.31 & 36.77 & 36.57 & 24.19 & 42.30 & 2.26 & $0.014 / 0.380$ & $0.044 / 0.406$ \\
\hline Trypsin (U/mgprot) & 887.64 & 1786.81 & 2572.52 & 2614.22 & 1808.80 & 185.16 & $0.046 / 0.273$ & $<0.001 / 0.831$ \\
\hline AKP (U/gprot) & 93.26 & 177.55 & 218.92 & 179.34 & 181.99 & 12.08 & $0.047 / 0.270$ & $0.001 / 0.694$ \\
\hline
\end{tabular}

*Values are means of triplicate. SEM, standard error of means; n.s., no significant difference was observed; AMS: amylase; LPS: lipase; AKP: alkaline phosphatase.

A

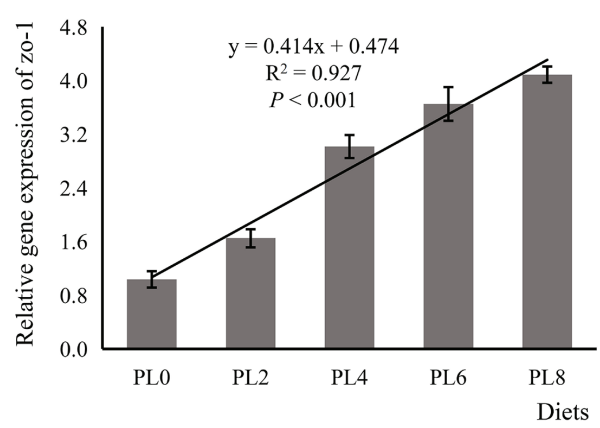

C

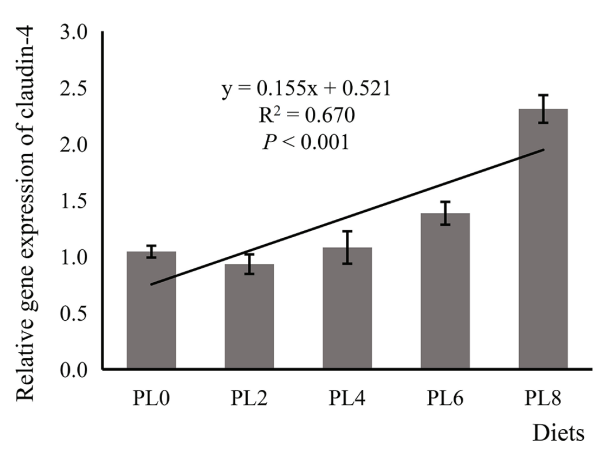

B

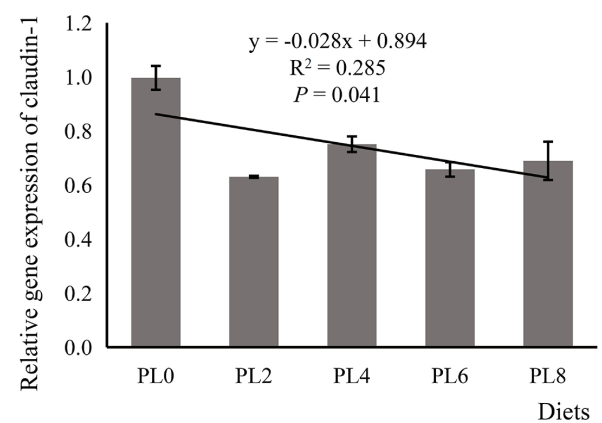

D

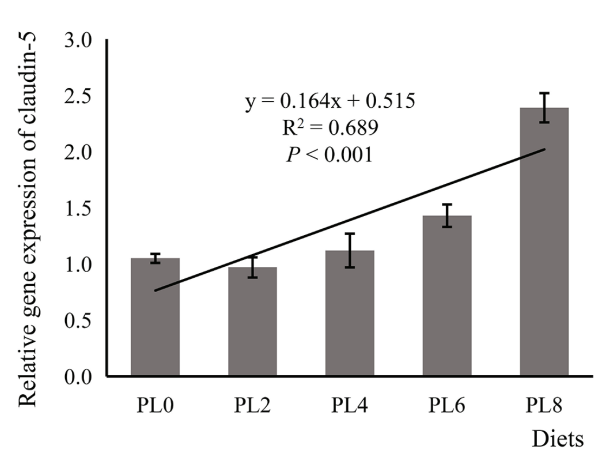

FIGURE 1 | Relative expression of tight junction proteins, including zona occludens-1 (ZO-1) (A), claudin-1 (B), claudin-4 (C), claudin-5 (D), in the intestine of larval largemouth bass fed diets with grade levels of phospholipids for 28 days. ZO-1: $P_{\text {linear }}<0.001, \mathrm{R}_{\text {linear }}^{2}=0.927 ; P_{\text {quadratic }}<0.001, \mathrm{R}_{\text {quadratic }}^{2}=0.952 ;$ claudin-1: $P_{\text {linear }}=$ $0.041, \mathrm{R}_{\text {linear }}^{2}=0.285 ; P_{\text {quadratic }}=0.021, \mathrm{R}_{\text {quadratic }}^{2}=0.474$; claudin-4: $P_{\text {linear }}<0.001, \mathrm{R}_{\text {linear }}^{2}=0.670 ; P_{\text {quadratic }}<0.001, \mathrm{R}_{\text {quadratic }}^{2}=0.900 ;$ claudin $-5: P_{\text {linear }}<$ $0.001, R_{\text {linear }}^{2}=0.689 ; P_{\text {quadratic }}<0.001, R_{\text {quadratic }}^{2}=0.902$. The "x" in the regression equation means the variation of dietary phospholipids content. 


\section{Intestinal TAG Content, Lysozyme Activity and Immune Response}

The increased supplementation of dietary phospholipids showed a significant negative relationship with the TAG content in intestine of larval largemouth bass $(P<0.05)$ (Figure 2). The activity of lysozyme was increased in a linear manner with the increase of dietary phospholipids $(P<0.05)$ (Figure 3). The expression of mapk14 was significantly down-regulated in a linear manner with the supplementation of phospholipids $(P<$ 0.05) (Figure 4). Meanwhile, the inclusion of dietary phospholipids slightly decreased the expression of mapk13 $(P>$ 0.05 ) (Figure 4). The expression of rela was decreased quadratically with the increase of dietary phospholipids $(P<$

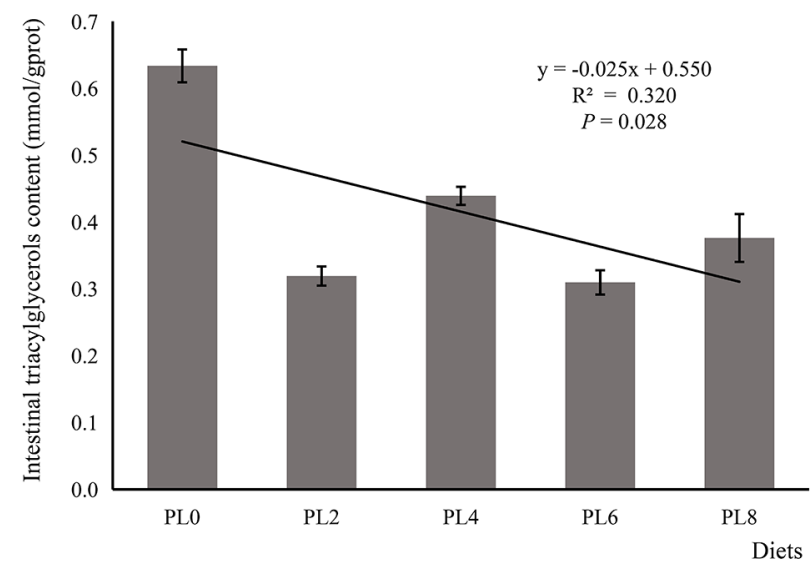

FIGURE 2 | The triacylglycerols content in intestine of larval largemouth bass fed diets with graded levels of phospholipids for 28 days. TAG: $P_{\text {linear }}=$ $0.028, R_{\text {linear }}^{2}=0.320 ; P_{\text {quadratic }}=0.011, R_{\text {quadratic }}^{2}=0.525$. The " $x$ " in the regression equation means the variation of dietary phospholipids content.

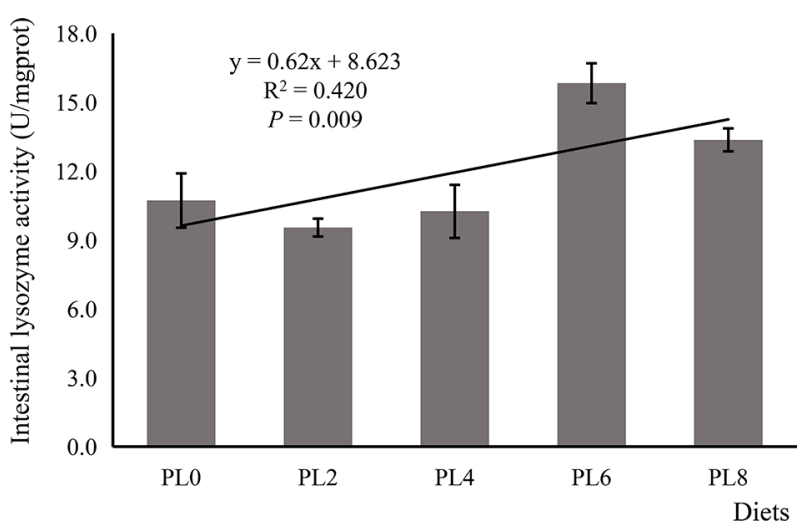

FIGURE 3 | The lysozyme activity in intestine of larval largemouth bass fed diets with graded levels of phospholipids for 28 days. $P_{\text {linear }}=0.009, \mathrm{R}_{\text {linear }}^{2}=$ $0.420 ; P_{\text {quadratic }}=0.037, R_{\text {quadratic }}^{2}=0.423$. The " $x$ " in the regression equation means the variation of dietary phospholipids content.
0.05) (Figure 4). The supplementation of dietary phospholipids led to linear down-regulation of $i l-1 \beta$ expression $(P<0.05)$ (Figure 5). Meanwhile, the expression of $\operatorname{tnf}-\alpha$ was also decreased linearly by dietary phospholipids $(P<0.05)$ (Figure 5). The inclusion of dietary phospholipids slightly depressed the expression of 5-lox, although no significant regression was observed $(P>0.05)$ (Figure 5). The expression of $\operatorname{tg} f-\beta$ was linearly increased with the inclusion of dietary phospholipids $(P<0.05)$ (Figure 5).

\section{Microbiota Composition and Diversity Analysis}

A total number of 278,896 sequences were obtained after being demultiplexed, quality screened and trimmed, which contained 858 OTUs with 97\% identity from 6 samples, and the raw reads were deposited into the NCBI Sequence Read Archive (SRA) database under accession number PRJNA767234. The OTUs were assigned to 638 species, 466 genera, 244 families, 136 orders, 54 class, and 26 phyla. The alpha diversity index, including Simpson, Shannon, Ace and Chao index, of the intestinal microbiota in larvae of PL8 group was slightly higher than that of the control group, but no significant differences were observed (Figure 6). The beta diversity index was estimated by principal coordinates analysis (PCoA) and non-metric multidimensional scaling (NMDS) ordination, and the results indicated that the intestinal bacterial in larvae of PL8 group was distinct from the control group (PL0) (Figure 7).

A bar map was used to graphically illustrate the variation in the dominant intestinal bacterial communities in response to dietary phospholipids at the phylum and genus level in PL0 (control) and PL8. The Proteobacteria, Firmicutes, and Actinomycetes were the dominant phyla in both treatments (Figure 8). However, Plesiomonas, Klebsiella and Lactococcus were detected as the predominant bacterial genera in the larval intestine of the control group, while Plesiomonas and Acinetobacter were the mainly intestine bacterial genera in the PL8 group (Figure 8). The Welch's-test revealed that phospholipids supplementation significantly elevated the relative abundance of Plesiomonas, Corynebacterium_1 and Macrococcus, but significantly decreased the abundance of Klebsiella $(P<0.05)$ (Figure 8).

The Venn diagram analysis revealed that 219 shared microbial genera were identified between the control group and PL8 group, and meanwhile, 37 and 210 unique bacterial genera were detected in the control group and PL8 group, respectively (Figure 9). The most abundant genera in the shared genera (> 10\%) were Plesiomonas $(51.49 \%)$ and Klebsiella (35.34\%) (Figure 9). The unique intestinal microbial genus $(>5 \%)$ in the larvae of the control group was Eubacterium fissicatena, Odoribacter, and genus unidentified Proteobacteria (Figure 9), and the unique genus $(>5 \%)$ in the larvae of PL8 group was Prevotella_7 and Prevotella (Figure 9).

LEfSe analysis was conducted to evaluate the differences in intestinal microbial community composition from the domain to the genus level between the control group and PL8 group, and significant differences in taxonomic distribution of intestinal microbiota communities were observed (Figure 10). The larval intestine of the control group exhibited significant enrichment 


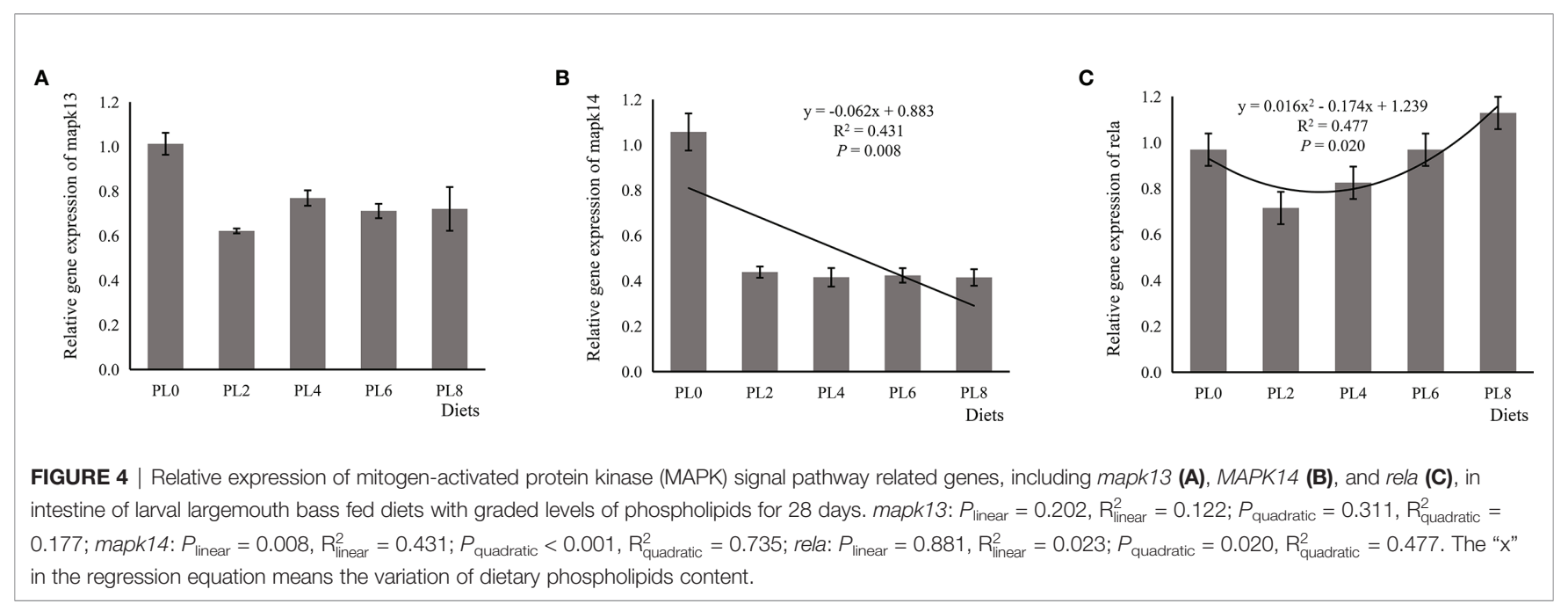

A

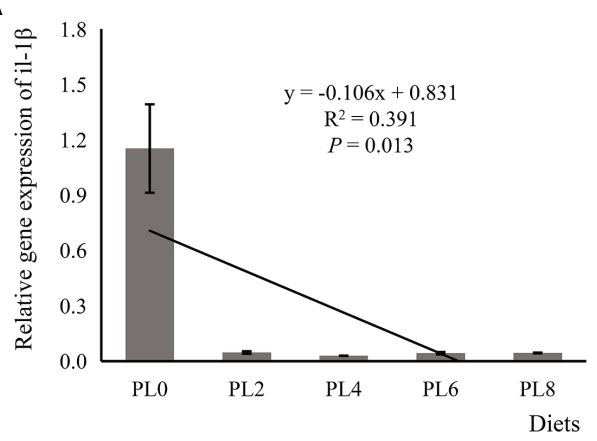

C

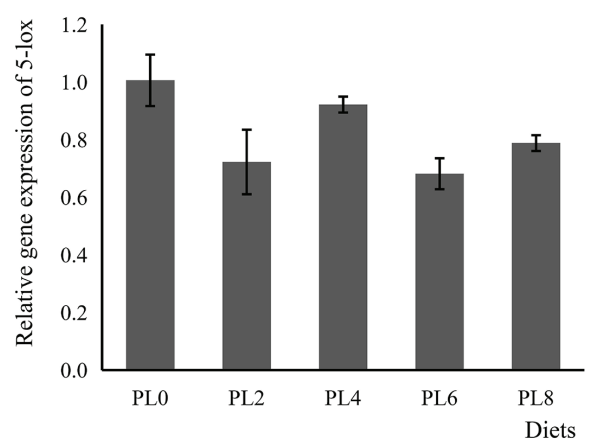

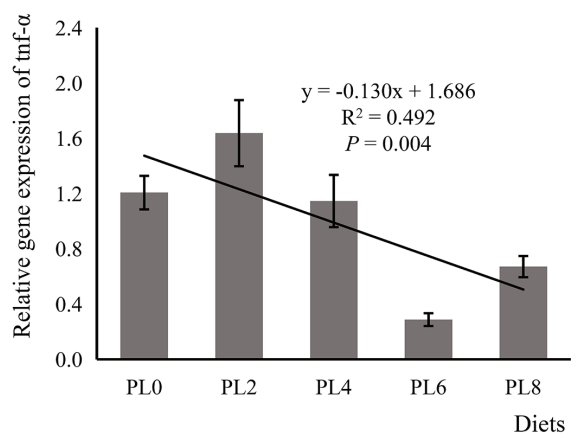

D

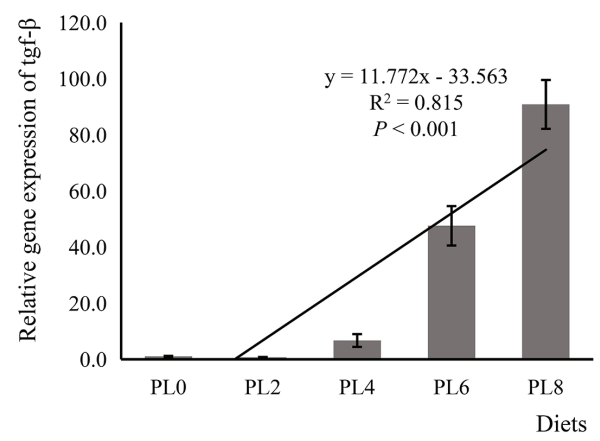

FIGURE 5 | Relative expression of pro-inflammatory, including interleukin-1 $\beta$ (il-1 $\beta$ ) (A), tumor necrosis factor- $\alpha$ (tnf- $\alpha$ ) (B), and 5-lipoxygenase (5-lox) (C), and antiinflammatory transforming growth factor $-\beta$ (tgf- $\beta$ ) (D) in intestine of larval largemouth bass fed diets with graded levels of phospholipids for 28 days. il- $1 \beta$ : $P_{\text {linear }}=$ $0.013, R_{\text {linear }}^{2}=0.391 ; P_{\text {quadratic }}=0.001, R_{\text {quadratic }}^{2}=0.695 ;$ tnf- $\alpha: P_{\text {linear }}=0.004, R_{\text {linear }}^{2}=0.492 ; P_{\text {quadratic }}=0.017, R_{\text {quadratic }}^{2}=0.493 ; 5$-lox: $P_{\text {linear }}=0.132, R_{\text {linear }}^{2}=$ $0.166 ; P_{\text {quadratic }}=0.239, R_{\text {quadratic }}^{2}=0.212 ; \operatorname{tgf}-\beta: P_{\text {linear }}=0.000, R_{\text {linear }}^{2}=0.815 ; P_{\text {quadratic }}<0.000, R_{\text {quadratic }}^{2}=0.956$. The "x" in the regression equation means the variation of dietary phospholipids content.

for order Enterobacteriales, family Enterobacteriaceae and genus Klebsiella, while high dietary phospholipids increased the relative abundance of Sulfurimonas (from phylum to genus), Macrococcus, Corynebacterium_1, Bifidobacterium, Acinetobacter, Thauera, and Thiobacillus (from order to genus) and Plesiomonas at the genus level (Figure 10).

\section{DISCUSSION}

It is well established that fish at larval stage possess a specific requirement for dietary phospholipids $(1,50)$. The improved growth performance caused by the inclusion of dietary phospholipids have been confirmed in some fish species, 


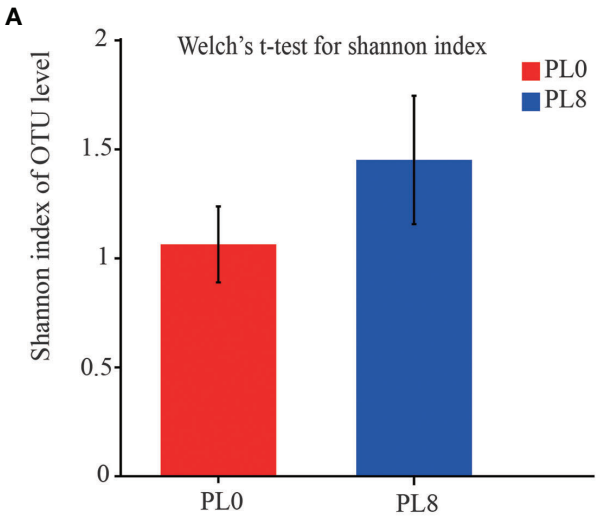

C

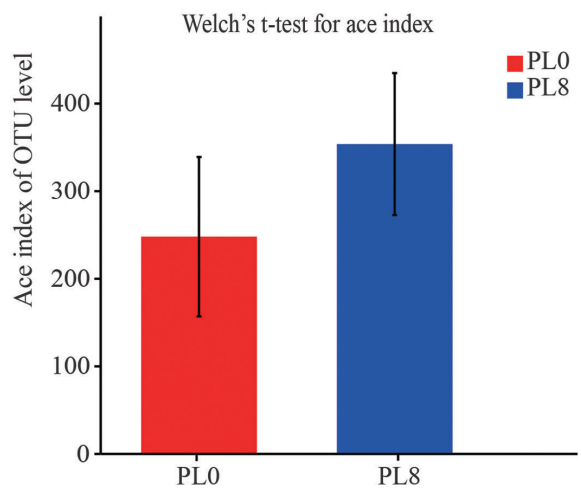

B

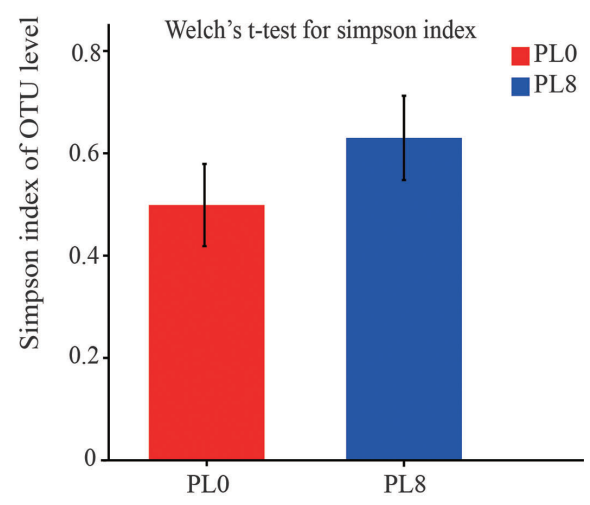

D

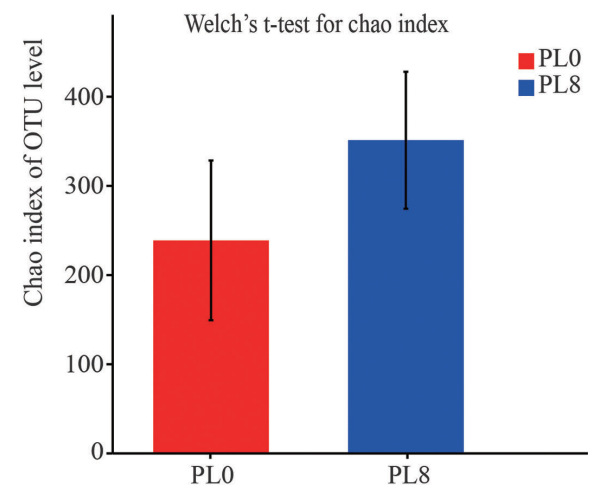

FIGURE 6 | The alpha diversity comparisons analysis, including Shannon diversity index (A), Simpson diversity index (B), Ace species richness index (C) and Chao species richness index (D) of microbial communities in the intestine of largemouth bass in the PLO (control) and PL8 groups. Values (mean \pm standard error of the mean, SEM) in bars that have the same letter are not significantly different $(P>0.05$; Welch's t-test) between treatments $(\mathrm{N}=3)$.

including European seabass, Pacific bluefin tuna (Thunnus orientalis), cobia (Rachycentron canadum), large yellow croaker, Dojo loach (Misgurnus anguillicaudatus), and hybrid grouper (Epinephelus fuscoguttatus $+\times$ E. lanceolatus $\left.{ }^{\text {तै }}\right)(4,6,7$, 51-53). Consistently, in the present study, the survival rate and specific growth rate were elevated with the supplementation of dietary phospholipids, and the maximum growth was observed in the PL8 group (9.29\% phospholipids). As no plateau was observed with the increasing dietary supplementation of phospholipids, it can be concluded that the minimal requirement of phospholipids for optimal growth in larval largemouth bass is at least $9.29 \%$, but possibly further improved performances could be achieved by higher supplementation levels. However, the findings of some previous studies revealed the dietary phospholipids requirement of larval freshwater fish (2-5\%) was relatively low, and typically lower than marine fish species (5-12\%) (1). Therefore, the relatively high phospholipids requirement observed here for the freshwater carnivorous fish largemouth bass seems to be a species-specific peculiarity, placing this species amongst marine larvae in terms of dietary phospholipids requirements. Prior to the feeding trail, the larvae were weaned with newly hatched artemia containing relative low phospholipids, about $4 \%$, which was possibly far from meeting the phospholipids requirement of larval largemouth bass. Thus, it cannot be excluded that the nutritional background of experimental fish may have also affected the requirement of largemouth bass larvae for phospholipids observed in this experiment.

The immature digestive tract of fish larvae seriously restricts the digestion and absorption of nutrients, and that is one of the main reasons why the culture of larval fish relies on live prey. Previous studies have demonstrated that dietary phospholipids supplementation can promote the development of digestive tract in some fish larvae (4-6). In general, a decreased amylose activity and increased alkaline phosphatase indicate the maturation of the digestive tract (4). Consistently, in the present study, the supplementation of phospholipids slightly decreased the activity of amylose, and meanwhile a significantly elevated alkaline phosphatase activity was recorded. 
A

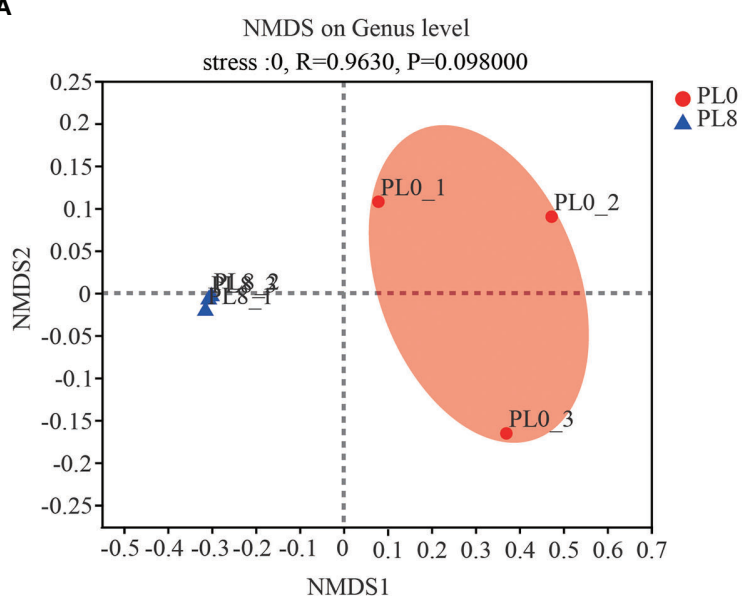

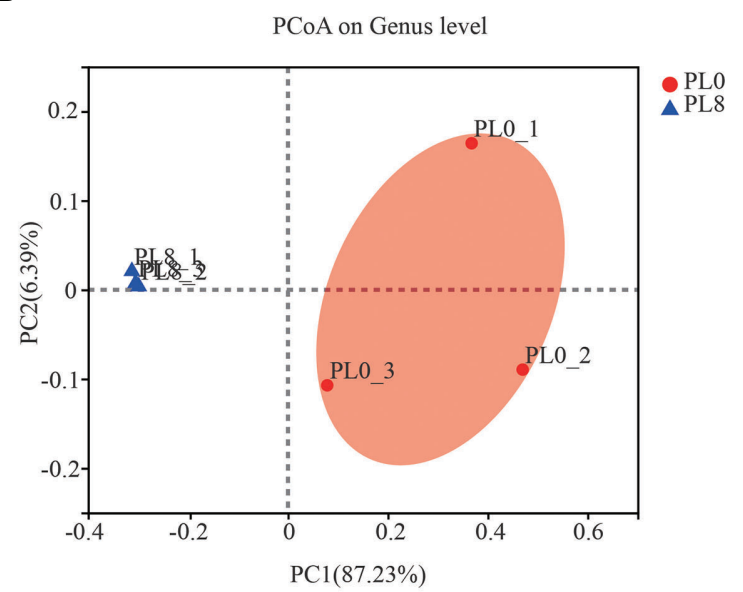

C

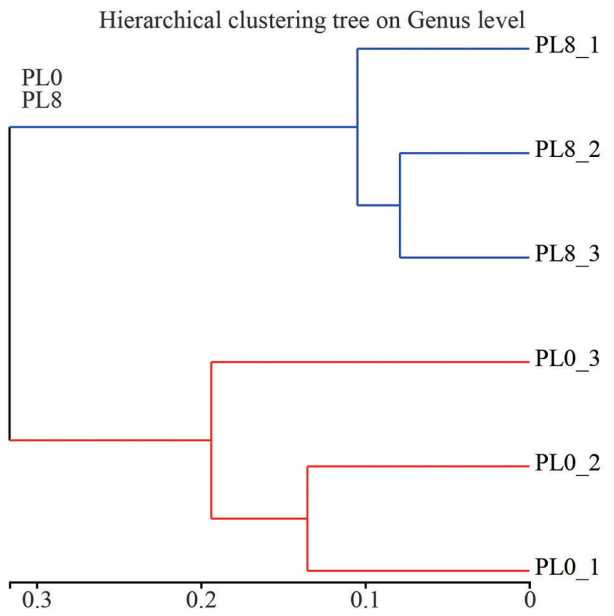

FIGURE 7 | The beta diversity comparisons analysis, including non-metric multidimensional scaling (NMDS) (A), principal component analysis (PCoA) (B), and hierarchical clustering tree analysis (C) of microbial communities at genus level in the intestine of largemouth bass fed the diets in the PLO (control) and PL8 groups.

Additionally, the activity of lipase and trypsin were linearly elevated with the supplementation of dietary phospholipids, and this was consistent with the increased lipase and trypsin activity that were also observed in some previous studies in the same species $(6,54)$. In summary, the variation in digestive enzyme activity confirmed the beneficial roles of dietary phospholipids in improving digestive tract development in largemouth bass larvae.

Tight junctions are key to epithelial adhesion and barrier function in mammals (11). The tight junction protein $\mathrm{ZO}-1$ acts as a bridge between the transmembrane protein occludin and cytoskeleton proteins (55). The downregulation of $z o-1$ expression caused the impairment of tight junction (56) and, in teleosts, was associated with the disrupted intestinal structural integrity $(14,57)$. In addition, the activation of claudin 1 , claudin 4 and claudin 5 are suggested to strengthen the junction of epithelial cells $(58,59)$. In the present study, the inclusion of dietary phospholipids was shown to directly up-regulate the expression of $z o-1$, claudin 4 and claudin 5, which confirmed the positive regulation of dietary phospholipids on intestinal structural integrity. Interestingly, the intercellular intestinal structural integrity has been reported to be inversely related to the expression of claudin 1 in largemouth bass (14), which was the opposite of what has been reported for mammals. Consistently, in the present study, the expression of claudin 1 was decreased in a linear manner with the inclusion of dietary phospholipids, and therefore favored the development of intestinal integrity. All these results observed on the digestive enzyme activities and the tight junction protein expression confirmed the beneficial roles of dietary phospholipids in the physiological and healthy development of the digestive tract of fish larvae.

An insufficient supply of dietary phospholipids has been reported to generally promote lipid accumulation in the 
A

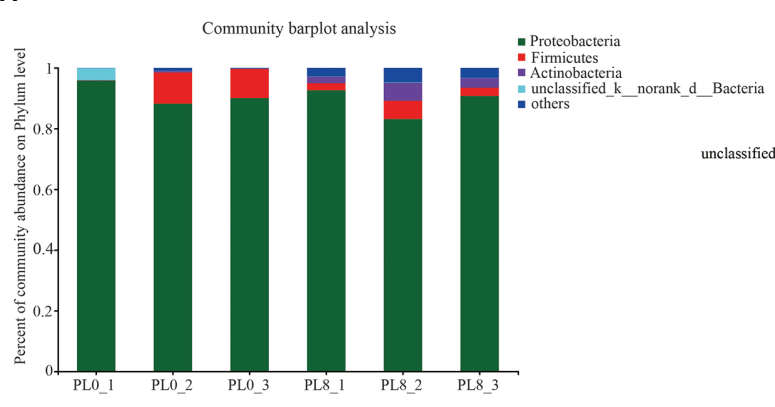

c

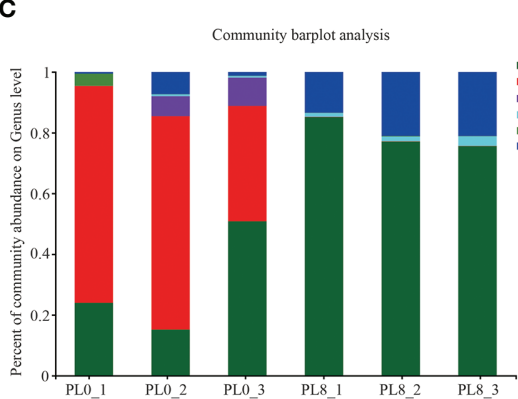

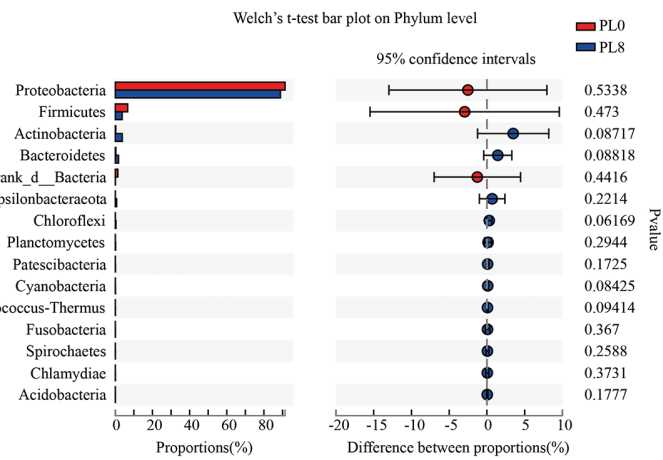

D

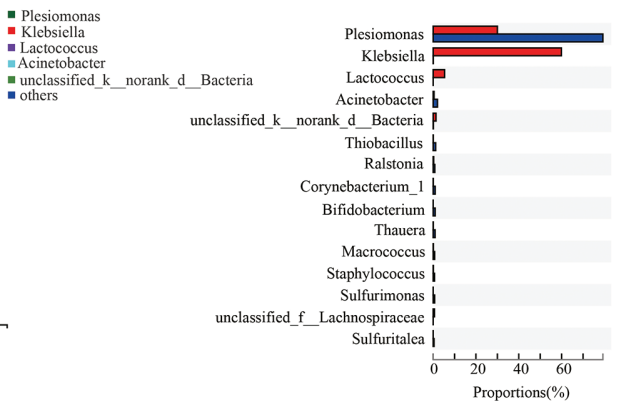

Welch's $\mathrm{t}$-test bar plot on Genus level

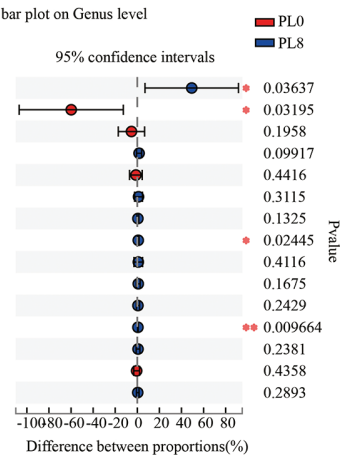

FIGURE 8 | Relative abundances (\%) of bacteria and comparison of bacterial abundances in the intestine of largemouth bass in the PLO (control) and PL8 groups. at the phylum (A, B) and genus (C, D) level, and the phyla and genus with relative abundances lower than $1 \%$ were assigned as "others", respectively. *0.01 < $\mathrm{P} \leq$ $0.05, * * 0.001<\mathrm{P} \leq 0.01$ (Welch's t-test, $\mathrm{N}=3$ ).

intestine of fish larvae, further resulting in intestinal histological damage $(18,19)$. This was suggested to be related to the limited phospholipids biosynthesis ability (16). In the present study, the supplementation of dietary phospholipids linearly decreased the TAG content in the intestine, with similar observation in larval gilthead sea bream (17) and common carp (18). This excessive lipid accumulation has been suggested to cause chronic inflammation in teleosts $(20,36)$. The immune barrier function, mainly depending on antibacterial compounds, such as lysozyme and cytokines, is also an important component of intestinal mucosal barriers (60). In the present study, the supplementation of dietary phospholipids proportionally increased the activity of intestinal lysozyme of largemouth bass. The increased lysozyme activity induced by dietary phospholipids inclusion has been observed in some fish species, such as Caspian brown trout (Salmo trutta caspius) (61), common carp (Cyprinus carpio) (62) and stellate sturgeon (Acipenser stellatus) (63). Cytokines, including proinflammatory and anti-inflammatory cytokines, are mainly responsible for the host innate defense in fish (64). The proinflammatory cytokine $t n f-\alpha$ is an important mediator in the regulation of inflammatory response, and its activation induces gene expression of some proinflammatory factors, such as $i l-1 \beta$, in rainbow trout (65). In the present study, the expression of proinflammatory cytokines, $\operatorname{tnf}-\alpha$ and $i l-1 \beta$, were repressed linearly with the increased supplementation of dietary phospholipids. The anti-inflammatory cytokines, such as $\operatorname{tg} f-\beta$, can depress the production of pro-inflammatory cytokine, and thereby inhibit the inflammatory response in teleost (66). In general, the expression of anti-inflammatory cytokines commonly followed an opposite pattern with that of pro-inflammatory cytokines, which was previously observed in some other fish species $(67,68$; 69). Consistently, the inclusion of dietary phospholipids was directly relative to the increase of the expression of $\operatorname{tgf}-\beta$. Therefore, the elevated lysozyme activity, reduced expression of pro-inflammatory cytokines, and improved gene expression of anti-inflammatory cytokines confirmed the contribution of dietary phospholipids in improving fish immune response.

In mammals, the pro-inflammatory cytokines, such as $\operatorname{tn} f-\alpha$ and $i l-1 \beta$, can be directly induced by the transcriptional factor, $n f-\kappa b(70)$. Previous studies have confirmed that the inhibition of rela, a member of $n f-\kappa b$ family with the function in regulating the transcription of target genes (71), decreased the expression of proinflammatory cytokines $(72,73)$. The positive relationship between the expression of rela and proinflammatory cytokines, such as $t n f-\alpha$ and $i l-1 \beta$, were widely 


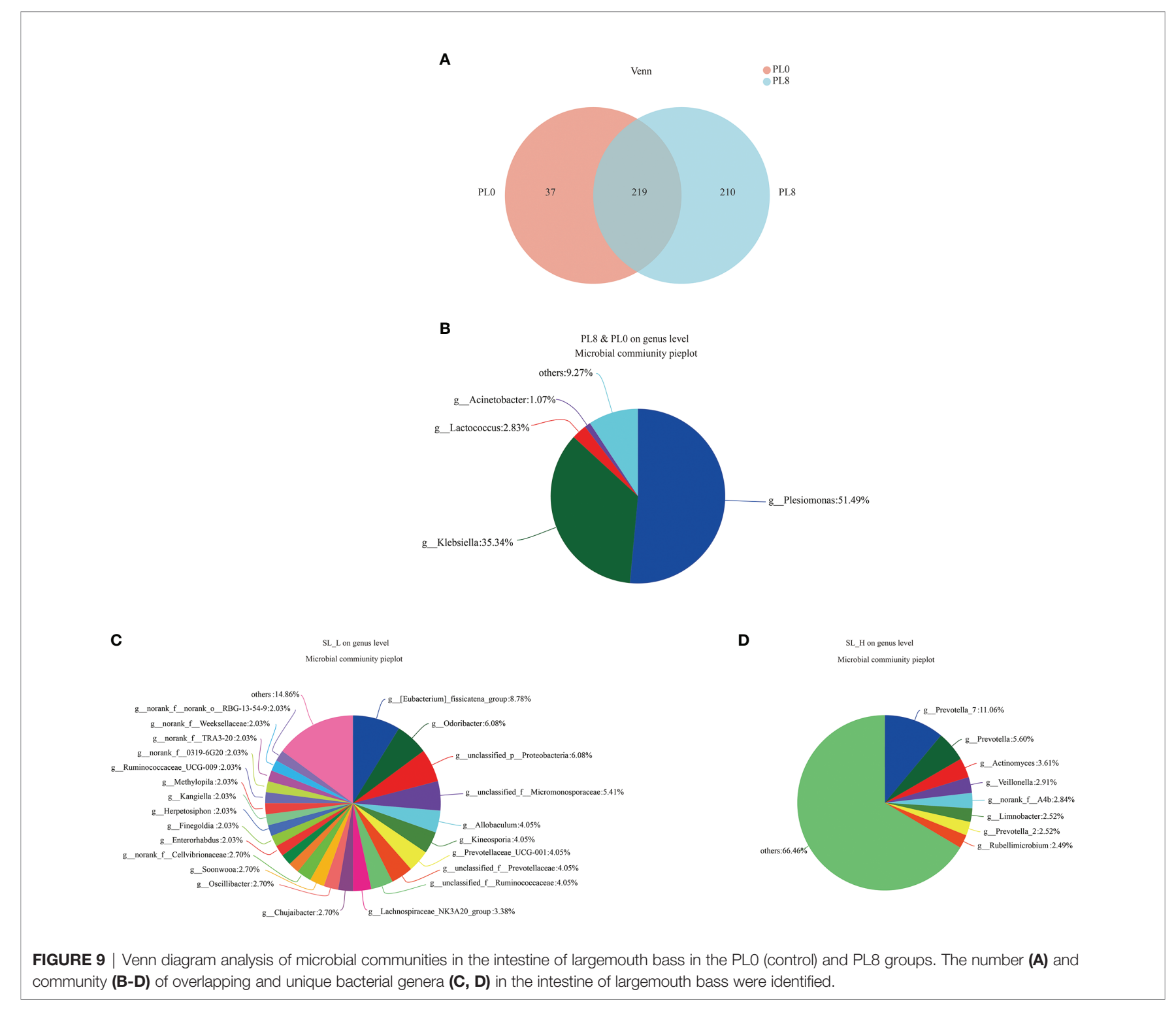

observed in some fish species, including grass crap (67), large yellow croaker (68) and hybrid grouper (69). In the present study, the inclusion of dietary phospholipids significantly decreased the expression of rela in a quadratic manner, followed a similar pattern with that of the proinflammatory cytokines. Moreover, $n f-\kappa b$ is a downstream target of the p38 MAPK signaling pathway, which is involved in the regulation of inflammation in mammals (22) and is suggested to influence the intestinal immune function of grass carp $(24,74)$. In the present study, the transcription of $p 38$ mapk, mapk 13 and mapk 14, was repressed with the inclusion of dietary phospholipids. The above results suggested that dietary phospholipids supplementation attenuated the inflammation response through the $\mathrm{p} 38 \mathrm{MAPK} / \mathrm{NF}-\kappa \mathrm{B}$ pathway.

The assembly of intestinal microbiota into distinct communities are important during the development of fish larvae (75). It is well demonstrated that dietary nutritional composition can affect the intestinal microbiota composition and diversity in fish species $(28,76,77)$. In the present study, dietary phospholipids supplementation produced no significant difference in the intestinal microbial community composition at the phyla level, and the Proteobacteria, Firmicutes, and Actinomycetes were the dominant phyla in both the two extreme treatments with the supplementation of phospholipids (PL8) or not (PL0, control), in accordance with previous studies reviewed by Borges etal. (78). However, the intestinal bacterial diversity was significantly affected at the genus level as dietary phospholipids increased. It's well confirmed that the intestinal microbiota plays an important role in the regulation of immune function and protection against pathogens (79). The inclusion of dietary phospholipids significantly decreased the richness of genera Klebsiella, an enterobacterium that was suggested to 


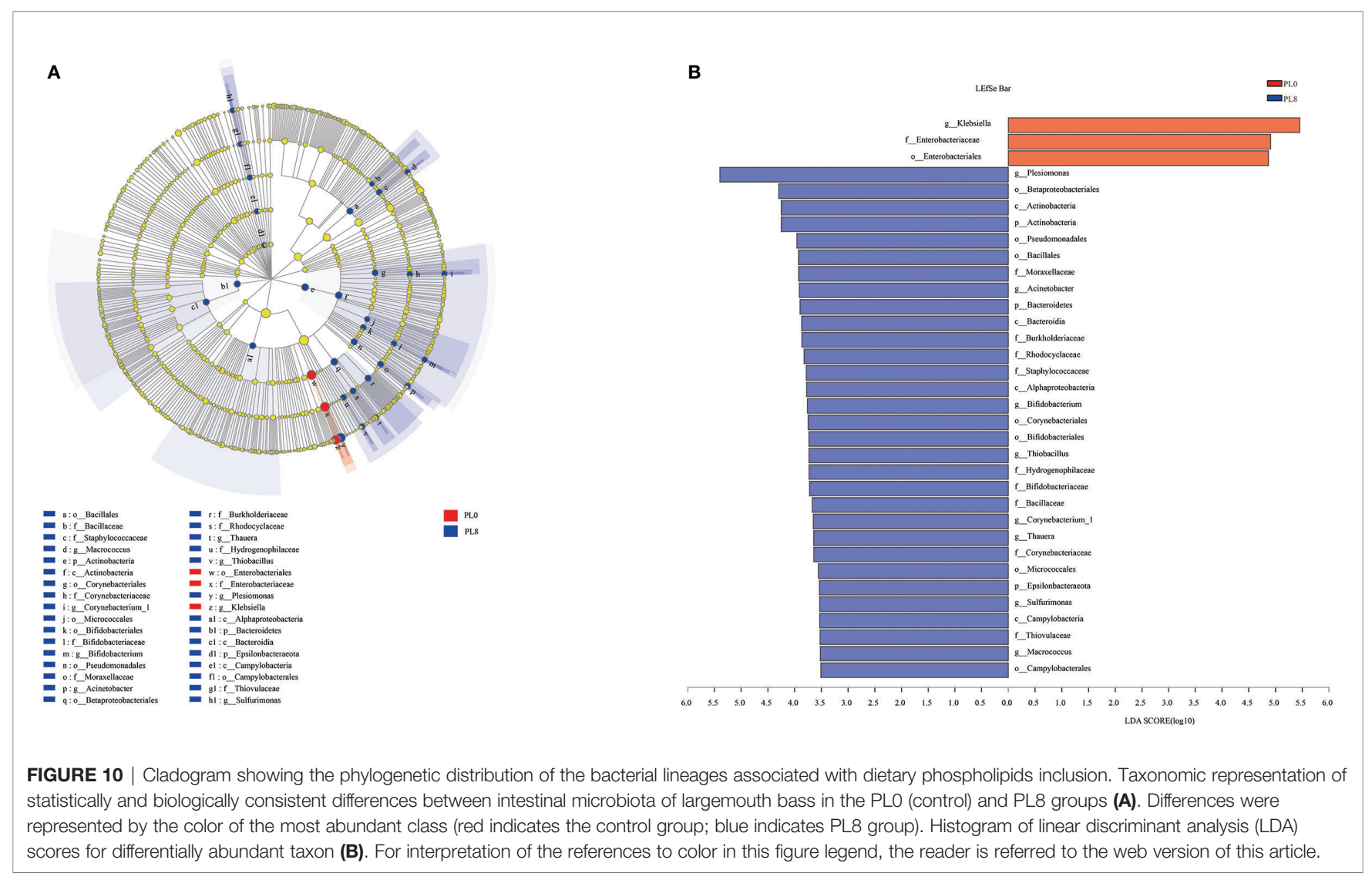

cause inflammation response through the p38 MAPK pathway $(80,81)$. The variation in the intestinal microbiota observed in the present study confirmed the beneficial role of dietary phospholipids in attenuating the inflammation response of largemouth bass larvae, and provided novel insights on possible mechanisms.

In conclusion, this study showed that larval largemouth bass have a specific requirement for phospholipids, that this requirement is equal or greater than $9.29 \%$, a requirement that is substantially higher compared to other freshwater species, and that the supplementation of dietary phospholipids significantly improved the growth performance and survival rate of the larvae. In addition, dietary phospholipids inclusion significantly improved the intestinal development, reduced inflammation response and modulated intestinal microbiota, which contributed to the beneficial roles of dietary phospholipids on the overall performance of largemouth bass larvae.

\section{DATA AVAILABILITY STATEMENT}

The original contributions presented in the study are publicly available. This data can be found here: National Center for Biotechnology Information (NCBI) BioProject database under accession number PRJNA767234.

\section{ETHICS STATEMENT}

The animal study was reviewed and approved by the Animal Care and Use Committee of the Shanghai Ocean University.

\section{AUTHOR CONTRIBUTIONS}

SW: investigation, formal analysis, and writing - original draft. $\mathrm{ZH}$ : investigation, methodology, and data curation. GT: methodology and writing - review \& editing. XW: investigation and methodology. ZF: investigation and methodology. NC: conceptualization, project administration, and funding acquisition. RX and HZ: investigation. SL: conceptualization, supervision, writing - review \& editing, and funding acquisition. All authors contributed to the article and approved the submitted version.

\section{FUNDING}

This work was financially supported by National Key R\&D Program of China (2019YFD0900203), China Agriculture Research System of MOF and MARA (CARS-46), Shanghai Talent Development Fund (2019097), and National Natural Science Foundation of China (31802308). 


\section{REFERENCES}

1. Tocher DR, Bendiksen EÅ, Campbell PJ, Bell JG. The Role of Phospholipids in Nutrition and Metabolism of Teleost Fish. Aquaculture (2008) 280(14):21-34. doi: 10.1016/j.aquaculture.2008.04.034

2. Turchini GM, Francis DS, Du ZY, Olsen RE, Ringo E, Tocher DR. The Lipids. In: RW Hardy, SJ Kaushik (Eds), San Diego: Academic Press. Fish Nutr (2022), 303-467.

3. Cahu CL, Gisbert E, Villeneuve LA, Morais S, Hamza N, Wold PA, et al. Influence of Dietary Phospholipids on Early Ontogenesis of Fish. Aquac Res (2009) 40(9):989-99. doi: 10.1111/j.1365-2109.2009.02190.x

4. Cahu CL, Infante JLZ, Barbosa V. Effect of Dietary Phospholipid Level and Phospholipid: Neutral Lipid Value on the Development of Sea Bass (Dicentrarchus Labrax) Larvae Fed a Compound Diet. Brit J Nutr (2003) 90 (1):21-8. doi: 10.1079/BJN2003880

5. Hamza N, Mhetli M, Khemis IB, Cahu C, Kestemont P. Effect of Dietary Phospholipid Levels on Performance, Enzyme Activities and Fatty Acid Composition of Pikeperch (Sander Lucioperca) Larvae. Aquaculture (2008) 275(1-4):274-82. doi: 10.1016/j.aquaculture.2008.01.014

6. Zhao J, Ai Q, Mai K, Zuo R, Luo Y. Effects of Dietary Phospholipids on Survival, Growth, Digestive Enzymes and Stress Resistance of Large Yellow Croaker, Larmichthys crocea larvae. Aquaculture (2013) 410:122-8. doi: 10.1016/j.aquaculture.2013.05.018

7. Huang Y, Xu J, Sheng Z, Chen N. Integrated Response of Growth Performance, Fatty Acid Composition, Antioxidant Responses and Lipid Metabolism to Dietary Phospholipids in Hybrid Grouper (Epinephelus Fuscoguttatus $\bigcirc \times$ E lanceolatus ${ }^{\wedge}$ ) Larvae. Aquaculture (2021) 541:736728. doi: 10.1016/j.aquaculture.2021.736728

8. Infante JZ, Cahu CL. Ontogeny of the Gastrointestinal Tract of Marine Fish Larvae. Comp Biochem Phys C (2001) 130(4):477-87. doi: 10.1016/s1095-6433 (00)80321-9

9. Cahu CL, Infante JZ. Early Weaning of Sea Bass (Dicentrarchus Labrax) Larvae With a Compound Diet: Effect on Digestive Enzymes. Comp Biochem Phys A (1994) 109(2):213-22. doi: 10.1016/0300-9629(94)90123-6

10. Cahu CL, Infante JZ. Effect of the Molecular Form of Dietary Nitrogen Supply in Sea Bass Larvae: Response of Pancreatic Enzymes and Intestinal Peptidases. Fish Physiol Biochem (1995) 14(3):209-14. doi: 10.1007/BF00004311

11. Niessen CM. Tight Junctions/Adherens Junctions: Basic Structure and Function.J Invest Dermatol (2007) 127(11):2525-32. doi: 10.1038/sj.jid.5700865

12. Gisbert E, Andree KB, Quintela JC, Calduch-Giner JA, Ipharraguerre IR, Pérez-Sánchez ,J. Olive Oil Bioactive Compounds Increase Body Weight, and Improve Gut Health and Integrity in Gilthead Sea Bream (Sparus Aurata). Brit J Nutr (2017) 117(3):351-63. doi: 10.1017/S0007114517000228

13. Chen L, Feng L, Jiang WD, Jiang J, Wu P, Zhao J, et al. Intestinal Immune Function, Antioxidant Status and Tight Junction Proteins mRNA Expression in Young Grass Carp (Ctenopharyngodon Idella) Fed Riboflavin Deficient Diet. Fish Shellfish Immun (2015) 47(1):470-84. doi: 10.1016/j.fsi.2015.09.037

14. Zhou YL, He GL, Jin T, Chen YJ, Dai FY, Luo L, et al. High Dietary Starch Impairs Intestinal Health and Microbiota of Largemouth Bass, Micropterus salmoides. Aquaculture (2021) 534:736261. doi: 10.1016/j.aquaculture. 2020.736261

15. Mansbach CM, Siddiqi SA. The Biogenesis of Chylomicrons. Annu Rev Physiol (2010) 72:315-33. doi: 10.1146/annurev-physiol-021909-135801

16. Carmona-Antoñanzas G, Taylor JF, Martinez-Rubio L, Tocher DR. Molecular Mechanism of Dietary Phospholipid Requirement of Atlantic Salmon, Salmo Salar, Fry. BBA-Mol Cell Biol L (2015) 1851(11):1428-41. doi: 10.1016/ j.bbalip.2015.08.006

17. Liu J, Caballero MJ, Izquierdo M, Ali TES, Hernandez-Cruz CM, Valencia A, et al. Necessity of Dietary Lecithin and Eicosapentaenoic Acid for Growth, Survival, Stress Resistance and Lipoprotein Formation in Gilthead Sea Bream Sparus aurata. Fisheries Sci (2002) 68(6):1165-72. doi: 10.1046/j.14442906.2002.00551.x

18. Fontagne S, Geurden I, Escaffre AM, Bergot P. Histological Changes Induced by Dietary Phospholipids in Intestine and Liver of Common Carp (Cyprinus Carpio L.) Larvae. Aquaculture (1998) 161(1-4):213-23. doi: 10.1016/S00448486(97)00271-8

19. Lu S, Zhao N, Zhao A, He R. Effect of Soybean Phospholipid Supplementation in Formulated Microdiets and Live Food on Foregut and Liver Histological
Changes of Pelteobagrus fulvidraco larvae. Aquaculture (2008) 278(1-4):11927. doi: 10.1016/j.aquaculture.2007.12.007

20. Wang T, Yan J, Xu W, Ai Q, Mai K. Characterization of Cyclooxygenase-2 and Its Induction Pathways in Response to High Lipid Diet-Induced Inflammation in. Larmichthys crocea Sci Rep (2016) 6(1):1-13. doi: 10.1038/ srep 19921

21. Li S, Sang C, Wang A, Zhang J, Chen N. Effects of Dietary Carbohydrate Sources on Growth Performance, Glycogen Accumulation, Insulin Signaling Pathway and Hepatic Glucose Metabolism in Largemouth Bass. Micropterus Salmoides Aquacult (2019) 513:734391. doi: 10.1016/j.aquaculture. 2019.734391

22. Cuadrado A, Nebreda AR. Mechanisms and Functions of P38 MAPK Signalling. Biochem J (2010) 429(3):403-17. doi: 10.1042/BJ20100323

23. Neurath MF, Pettersson S. Predominant Role of NF-kb P65 in the Pathogenesis of Chronic Intestinal Inflammation. Immunobiology (1997) 198(1-3):91-8. doi: 10.1016/S0171-2985(97)80030-7

24. Huang D, Maulu S, Ren M, Liang H, Ge X, Ji K, et al. Dietary Lysine Levels Improved Antioxidant Capacity and Immunity via the TOR and P38 MAPK Signaling Pathways in Grass Carp, Ctenopharyngodon Idellus Fry. Front Immuno (2021) 12:122. doi: 10.3389/fimmu.2021.635015

25. Nayak SK. Role of Gastrointestinal Microbiota in Fish. Aquac Res (2010) 41 (11):1553-73. doi: 10.1111/j.1365-2109.2010.02546.x

26. Rawls JF, Samuel BS, Gordon JI. Gnotobiotic Zebrafish Reveal Evolutionarily Conserved Responses to the Gut Microbiota. Proc Natl Acad Sci USA (2004) 101(13):4596-601. doi: 10.1073/pnas.0400706101

27. Ringø E, Myklebust R, Mayhew TM, Olsen RE. Bacterial Translocation and Pathogenesis in the Digestive Tract of Larvae and Fry. Aquaculture (2007) 268 (1-4):251-64. doi: 10.1016/j.aquaculture.2007.04.047

28. Ringø E, Zhou Z, Vecino JG, Wadsworth S, Romero J, Krogdahl Å, et al. Effect of Dietary Components on the Gut Microbiota of Aquatic Animals. A NeverEnding Story? Aquacult Nutr (2016) 22(2):219-82. doi: 10.1111/anu.12346

29. Guo X, Ran C, Zhang Z, He S, Jin M, Zhou Z. The Growth-Promoting Effect of Dietary Nucleotides in Fish Is Associated With an Intestinal MicrobiotaMediated Reduction in Energy Expenditure. J Nutr (2017) 147(5):781-8. doi: 10.3945/jn.116.245506

30. Parolini C. Effects of Fish N-3 PUFAs on Intestinal Microbiota and Immune System. Mar Drugs (2019) 17(6):374. doi: 10.3390/md17060374

31. Ministry of Agriculture and Rural Affairs, China. China Fishery Statistics Yearbook. Beijing: China Agriculture Press (2020).

32. Chen P, Wu X, Gu X, Han J, Xue M, Liang X. FoxO1 in Micropterus Salmoides: Molecular Characterization and Its Roles in Glucose Metabolism by Glucose or Insulin-Glucose Loading. Gen Comp Endocr (2021) 310:113811. doi: 10.1016/j.ygcen.2021.113811

33. Xie S, Yin P, Tian L, Liu Y, Niu J. Lipid Metabolism and Plasma Metabolomics of Juvenile Largemouth Bass Micropterus Salmoides Were Affected by Dietary Oxidized Fish Oil. Aquaculture (2020) 522:735158. doi: 10.1016/ j.aquaculture.2020.735158

34. Yin P, Xie S, Huo Y, Guo T, Fang H, Zhang Y, et al. Effects of Dietary Oxidized Fish Oil on Growth Performance, Antioxidant Defense System, Apoptosis and Mitochondrial Function of Juvenile Largemouth Bass (Micropterus Salmoides). Aquaculture (2019) 500:347-58. doi: 10.1016/j.aquaculture. 2018.09.009

35. Li S, Sang C, Turchini GM, Wang A, Zhang J, Chen N. Starch in Aquafeeds: The Benefits of a High Amylose to Amylopectin Ratio and Resistant Starch Content in Diets for the Carnivorous Fish, Largemouth Bass (Micropterus Salmoides). Brit J Nutr (2020) 124(11):1145-55. doi: 10.1017/S0007114520002214

36. Li X, Cui K, Fang W, Chen Q, Xu D, Mai K, et al. High Level of Dietary Olive Oil Decreased Growth, Increased Liver Lipid Deposition and Induced Inflammation by Activating the P38 MAPK and JNK Pathways in Large Yellow Croaker (Larimichthys Crocea). Fish Shellfish Immun (2019) 94:15765. doi: $10.1016 /$ j.fsi.2019.08.062

37. Association of Official Analytical Chemist (AOAC). Official Methods of Analysis, 17th Ed. Arlington, VA: AOAC, Inc (2003).

38. Floch J. A Simple Method for the Isolation and Purification of Total Lipids From Animal Tissues. J Biol Chem (1957) 226:497-509. doi: 10.1016/S00219258(18)64849-5

39. Peng M, Xu W, Mai K, Zhou H, Zhang Y, Liufu Z, et al. Growth Performance, Lipid Deposition and Hepatic Lipid Metabolism Related Gene Expression in 
Juvenile Turbot (Scophthalmus Maximus L.) Fed Diets With Various Fish Oil Substitution Levels by Soybean Oil. Aquaculture (2014) 433:442-9. doi: 10.1016/j.aquaculture.2014.07.005

40. Li BQ, Deng YJ, Suo XB. Determinating Contents of Phospholipids in Liposomal Gel With Molybdenum Blue Method. Chin J Pharm (2005) 3:306-10. doi: 10.14146/j.cnki.cjp.2005.05.022

41. Bradford MM. A Rapid and Sensitive Method for the Quantitation of Microgram Quantities of Protein Utilizing the Principle of Protein-Dye Binding. Anal Biochem (1976) 72(1-2):248-54. doi: 10.1016/0003-2697(76) 90527-3

42. Schwartz DM, Wolins NE. A Simple and Rapid Method to Assay Triacylglycerol in Cells and Tissues. J Lipid Res (2007) 48(11):2514-20. doi: 10.1194/jlr.D700017-JLR200

43. Yang P, Wang W, Chi S, Mai K, Song F, Wang L. Effects of Dietary Lysine on Regulating GH-IGF System, Intermediate Metabolism and Immune Response in Largemouth Bass (Micropterus Salmoides). Aquacult Rep (2020) 17:100323. doi: 10.1016/j.aqrep.2020.100323

44. Livak KJ, Schmittgen TD. Analysis of Relative Gene Expression Data Using Real-Time Quantitative PCR and the $2^{-\triangle \Delta C T}$ Method. Methods (2001) 25 (4):402-8. doi: 10.1006/meth.2001.1262

45. Caporaso JG, Kuczynski J, Stombaugh J, Bittinger K, Bushman FD, Costello EK, et al. QIIME Allows Analysis of High-Throughput Community Sequencing Data. Nat Methods (2010) 7(5):335-6. doi: 10.1038/nmeth.f.303

46. Magoč T, Salzberg SL. FLASH: Fast Length Adjustment of Short Reads to Improve Genome Assemblies. Bioinformatics (2011) 27(21):2957-63. doi: 10.1093/bioinformatics/btr507

47. Edgar RC. UPARSE: Highly Accurate OTU Sequences From Microbial Amplicon Reads. Nat Methods (2013) 10(10):996-8. doi: 10.1038/nmeth.2604

48. Wang Q, Garrity GM, Tiedje JM, Cole JR. Naive Bayesian Classifier for Rapid Assignment of rRNA Sequences Into the New Bacterial Taxonomy. Appl Environ Microb (2007) 73(16):5261-7. doi: 10.1128/ AEM.00062-07

49. Segata N, Izard J, Waldron L, Gevers D, Miropolsky L, Garrett WS, et al. Metagenomic Biomarker Discovery and Explanation. Genome Biol (2011) 12 (6):1-18. doi: 10.1186/gb-2011-12-6-r60

50. Sargent JR, Tocher DR, Bell JG. The Lipids. In: JE Halver, RW Hardy, editors. Fish Nutrition. San Diego: Academic Press (2002). p. 2-181.

51. Seoka M, Kurata M, Tamagawa R, Biswas AK, Biswas BK, Yong ASK, et al. Dietary Supplementation of Salmon Roe Phospholipid Enhances the Growth and Survival of Pacific Bluefin Tuna Thunnus Orientalis Larvae and Juveniles Aquaculture (2008) 275(1-4):225-34. doi: 10.1016/ j.aquaculture.2007.12.027

52. Niu J, Liu YJ, Tian LX, Mai KS, Yang HJ, Ye CX, et al. Effects of Dietary Phospholipid Level in Cobia (Rachycentron Canadum) Larvae: Growth, Survival, Plasma Lipids and Enzymes of Lipid Metabolism. Fish Physiol Biochem (2008) 34(1):9-17. doi: 10.1007/s10695-007-9140-y

53. Gao J, Koshio S, Wang W, Li Y, Huang S, Cao X. Effects of Dietary Phospholipid Levels on Growth Performance, Fatty Acid Composition and Antioxidant Responses of Dojo Loach Misgurnus Anguillicaudatus Larvae. Aquaculture (2014) 426:304-9. doi: 10.1016/j.aquaculture. 2014.02.022

54. Cai Z, Feng S, Xiang X, Mai K, Ai Q. Effects of Dietary Phospholipid on Lipase Activity, Antioxidant Capacity and Lipid Metabolism-Related Gene Expression in Large Yellow Croaker Larvae (Larimichthys Crocea). Comp Biochem Phys B (2016) 201:46-52. doi: 10.1016/j.cbpb.2016.06.007

55. Fanning AS, Jameson BJ, Jesaitis LA, Anderson JM. The Tight Junction Protein ZO-1 Establishes a Link Between the Transmembrane Protein Occludin and the Actin Cytoskeleton. J Biol Chem (1998) 273(45):2974553. doi: $10.1074 / \mathrm{jbc} .273 .45 .29745$

56. Balda MS, Matter K. The Tight Junction Protein ZO-1 and an Interacting Transcription Factor Regulate ErbB-2 Expression. EMBO J (2000) 19 (9):2024-33. doi: 10.1093/emboj/19.9.2024

57. Zhang YL, Duan XD, Feng L, Jiang WD, Wu P, Liu Y, et al. Soybean Glycinin Disrupted Intestinal Structural Integrity Related to Aggravation of Apoptosis and Downregulated Transcription of Tight Junction Proteins in the Intestine of Juvenile Grass Carp (Ctenopharyngodon Idella). Aquaculture (2021) 531:735909. doi: 10.1016/j.aquaculture.2020.735909
58. Oliveira SS, Morgado-Diaz JA. Claudins: Multifunctional Players in Epithelial Tight Junctions and Their Role in Cancer. Cell Mol Life Sci (2007) 64(1):1728. doi: 10.1007/s00018-006-6314-1

59. Krause G, Winkler L, Mueller SL, Haseloff RF, Piontek J, Blasig IE. Structure and Function of Claudins. BBA-Biomembranes (2008) 1778(3):631-45. doi: 10.1016/j.bbamem.2007.10.018

60. Magnadóttir B. Innate Immunity of Fish (Overview). Fish Shellfish Immun (2006) 20(2):137-51. doi: 10.1016/j.fsi.2004.09.006

61. Haghparast RJ, Moghanlou KS, Mohseni M, Imani A. Effect of Dietary Soybean Lecithin on Fish Performance, Hemato-Immunological Parameters, Lipid Biochemistry, Antioxidant Status, Digestive Enzymes Activity and Intestinal Histomorphometry of Pre-Spawning Caspian Brown Trout (Salmo Trutta Caspius). Fish Shellfish Immun (2019) 91:50-7. doi: 10.1016/j.fsi.2019.05.022

62. Adel M, Gholaghaie M, Khanjany P, Citarasu T. Effect of Dietary Soybean Lecithin on Growth Parameters, Digestive Enzyme Activity, Antioxidative Status and Mucosal Immune Responses of Common Carp (Cyprinus Carpio) Aquacult Nutr (2017) 23(5):1145-52. doi: 10.1111/anu.12483

63. Jafari F, Agh N, Noori F, Tokmachi A, Gisbert E. Effects of Dietary Soybean Lecithin on Growth Performance, Blood Chemistry and Immunity in Juvenile Stellate Sturgeon (Acipenser Stellatus). Fish Shellfish Immun (2018) 80:487-96. doi: $10.1016 /$ j.fsi.2018.06.023

64. Savan R, Sakai M. Genomics of Fish Cytokines. Comp Biochem Phys D (2006) 1(1):89-101. doi: 10.1016/j.cbd.2005.08.005

65. Zou J, Peddie S, Scapigliati G, Zhang Y, Bols NC, Ellis AE, et al. Functional Characterisation of the Recombinant Tumor Necrosis Factors in Rainbow Trout, Oncorhynchus mykiss. Dev Comp Immunol (2003) 27(9):813-22. doi: 10.1016/S0145-305X(03)00077-6

66. Verburg-Van Kemenade BL, Stolte EH, Metz JR, Chadzinska M. Neuroendocrine-Immune Interactions in Teleost Fish. Fish Physiol (2009) 28:313-64. doi: 10.1016/S1546-5098(09)28007-1

67. Feng L, Chen YP, Jiang WD, Liu Y, Jiang J, Wu P, et al. Modulation of Immune Response, Physical Barrier and Related Signaling Factors in the Gills of Juvenile Grass Carp (Ctenopharyngodon Idella) Fed Supplemented Diet With Phospholipids. Fish Shellfish Immun (2016) 48:79-93. doi: 10.1016/ j.fsi.2015.11.020

68. Tan P, Dong X, Mai K, Xu W, Ai Q. Vegetable Oil Induced Inflammatory Response by Altering TLR-NF- $\mathrm{kb}$ Signalling, Macrophages Infiltration and Polarization in Adipose Tissue of Large Yellow Croaker (Larimichthys Crocea). Fish Shellfish Immun (2016) 59:398-405. doi: 10.1016/j.fsi.2016.11.009

69. Li S, Wang A, Li Z, Zhang J, Sang C, Chen N. Antioxidant Defenses and nonSpecific Immunity at Enzymatic and Transcriptional Levels in Response to Dietary Carbohydrate in a Typical Carnivorous Fish, Hybrid Grouper (Epinephelus Fuscoguttatus $\bigcirc \times$ E. Lanceolatus $\bigcirc$ ). Fish Shellish Immun (2020) 100:109-16. doi: 10.1016/j.fsi.2020.03.015

70. Baeuerle PA, Baichwal VR. NF-kB as a Frequent Target for Immunosuppressive and Anti-Inflammatory Molecules. Adv Immunol (1997) 65:111-38. doi: 10.1016/S0065-2776(08)60742-7

71. Siebenlist U, Franzoso G, Brown K. Structure, Regulation and Function of NFkappaB. Annu Rev Cell Dev Bi (1994) 10(1):405-55. doi: 10.1146/annurev. cb.10.110194.002201

72. Li Z, Zhang DK, Yi WQ, Ouyang Q, Chen YQ, Gan HT. NF-Kb P65 Antisense Oligonucleotides may Serve as a Novel Molecular Approach for the Treatment of Patients With Ulcerative Colitis. Arch Med Res (2008) 39(8):729-34. doi: 10.1016/j.arcmed.2008.08.001

73. Danning CL, Illei GG, Hitchon C, Greer MR, Boumpas DT, McInnes IB. Macrophage-Derived Cytokine and Nuclear Factor $\mathrm{kb}$ P65 Expression in Synovial Membrane and Skin of Patients With Psoriatic Arthritis. Arthritis Rheum-US (2000) 43(6):1244-56. doi: 10.1002/1529-0131(200006) 43:6<1244::AID-ANR7>3.0.CO;2-2

74. Li L, Feng L, Jiang WD, Jiang J, Wu P, Zhao J, et al. Dietary Pantothenic Acid Depressed the Gill Immune and Physical Barrier Function via NF-kb, TOR, Nrf2, P38mapk and MLCK Signaling Pathways in Grass Carp (Ctenopharyngodon Idella). Fish Shellfish Immun (2015) 47(1):500-10. doi: 10.1016/j.fsi.2015.09.038

75. Stephens WZ, Burns AR, Stagaman K, Wong S, Rawls JF, Guillemin K, et al. The Composition of the Zebrafish Intestinal Microbial Community Varies Across Development. ISME J (2016) 10(3):644-54. doi: 10.1038/ismej.2015.140 
76. Zhou JS, Chen HJ, Ji H, Shi XC, Li XX, Chen LQ, et al. Effect of Dietary Bile Acids on Growth, Body Composition, Lipid Metabolism and Microbiota in Grass Carp (Ctenopharyngodon Idella). Aquacult Nutr (2018) 24(2):802-13. doi: 10.1111/anu.12609

77. Nikouli E, Kormas KA, Jin Y, Olsen Y, Bakke I, Vadstein O. Dietary Lipid Effects on Gut Microbiota of First Feeding Atlantic Salmon (Salmo Salar L.). Front Mar Sci (2021) 665576. doi: 10.3389/fmars.2021.665576

78. Borges N, Keller-Costa T, Sanches-Fernandes GM, Louvado A, Gomes NC, Costa R. Bacteriome Structure, Function, and Probiotics in Fish Larviculture: The Good, the Bad, and the Gaps. Annu Rev Anim Biosci (2021) 9:423-52. doi: 10.1146/annurev-animal-062920-113114

79. Hooper LV, Littman DR, Macpherson AJ. Interactions Between the Microbiota and the Immune System. Science (2012) 336(6086):1268-73. doi: $10.1126 /$ science. 1223490

80. Wu JH, Hong LC, Tsai YY, Chen HW, Chen WX, Wu TS. Mitogen-Activated Protein Kinase (MAPK) Signalling Pathways in HepG2 Cells Infected With a Virulent Strain of Klebsiella Pneumoniae. Cell Microbiol (2006) 8(9):1467-74. doi: 10.1111/j.1462-5822.2006.00725.x

81. Tang Q, Wang Q, Sun Z, Kang S, Fan Y, Hao Z. Bergenin Monohydrate Attenuates Inflammatory Response via MAPK and NF- $\mathrm{b}$ Pathways Against
Klebsiella Pneumonia Infection. Front Pharmacol (2021) 12. doi: 10.3389/ fphar.2021.651664

Conflict of Interest: The authors declare that the research was conducted in the absence of any commercial or financial relationships that could be construed as a potential conflict of interest.

Publisher's Note: All claims expressed in this article are solely those of the authors and do not necessarily represent those of their affiliated organizations, or those of the publisher, the editors and the reviewers. Any product that may be evaluated in this article, or claim that may be made by its manufacturer, is not guaranteed or endorsed by the publisher.

Copyright (C) 2022 Wang, Han, Turchini, Wang, Fang, Chen, Xie, Zhang and Li. This is an open-access article distributed under the terms of the Creative Commons Attribution License (CC BY). The use, distribution or reproduction in other forums is permitted, provided the original author(s) and the copyright owner(s) are credited and that the original publication in this journal is cited, in accordance with accepted academic practice. No use, distribution or reproduction is permitted which does not comply with these terms. 